\section{A) Check for updates}

Cite this: Dalton Trans., 2021, 50 17346

Received 2nd September 2021, Accepted 1st November 2021

DOI: 10.1039/d1dt02964a

rsc.li/dalton

\title{
Single source precursor route to nanometric tin chalcogenides $\uparrow$
}

\author{
Veronika Brune, (D) *a Nidal Raydan, ${ }^{\mathrm{b}}$ Anja Sutorius, ${ }^{\mathrm{a}}$ Fabian Hartl, \\ Bhagyesh Purohit, ${ }^{\mathrm{b}}$ Sweta Gahlot, ${ }^{\text {b }}$ Pascal Bargiela, ${ }^{\mathrm{b}}$ Laurence Burel, ${ }^{\mathrm{b}}$ \\ Michael Wilhelm, ${ }^{a}$ Corinna Hegemann, ${ }^{a}$ Ufuk Atamtürk, ${ }^{a}$ Sanjay Mathur (D) a and \\ Shashank Mishra (D) *b
}

\begin{abstract}
Low-temperature solution phase synthesis of nanomaterials using designed molecular precursors enjoys tremendous advantages over traditional high-temperature solid-state synthesis. These include atomiclevel control over stoichiometry, homogeneous elemental dispersion and uniformly distributed nanoparticles. For exploiting these advantages, however, rationally designed molecular complexes having certain properties are usually required. We report here the synthesis and complete characterization of new molecular precursors containing direct $\mathrm{Sn}-\mathrm{E}$ bonds ( $\mathrm{E}=\mathrm{S}$ or $\mathrm{Se}$ ), which undergo facile decomposition under different conditions (solid/solution phase, thermal/microwave heating, single/mixed solvents, varying temperatures, etc.) to afford phase-pure or mixed-phase tin chalcogenide nanoflakes with defined ratios.
\end{abstract}

\section{Introduction}

Two-dimensional atomically thin semiconductor nanostructures, like tin monochalcogenides $\operatorname{SnE}(E=S, S n)$ and tin dichalogenides $\mathrm{SnE}_{2}(\mathrm{E}=\mathrm{S}$, Se), have been attracting worldwide attention due to their exceptional electrical and optical properties, and their potential applications in nanoscale electronics, photonics and functional materials as well as semiconducting and optical devices. ${ }^{1-5}$ Mono or few layered 2D van der Waals (vdW) tin-based chalcogenide materials are distinguished in their chemical and physical properties ${ }^{6,7}$ as compared to their bulk counterparts. Additionally, these layered vdW materials have the advantage of their constituent elements being abundant in nature and not posing any health and environmental hazards. ${ }^{8-10}$ The versatile coordinating characteristics of tin and the chalcogenides sulfur and selenium permit tin sulfide/selenide to adopt a variety of phases ( $\mathrm{SnE}, \mathrm{Sn}_{2} \mathrm{E}_{3}$, and $\mathrm{SnE}_{2} ; \mathrm{E}=\mathrm{S}, \mathrm{Se}$ ). ${ }^{9,11}$ On the other hand, this variety of stable crystal phases presents a challenge to the targeted material preparation, meaning that the composition or phase purity is compromised by the coexistence of different

\footnotetext{
${ }^{a}$ University of Cologne, Institute of Inorganic Chemisty, Greinstraße 6, 50939 Cologne, Germany. E-mail: veronika.brune@uni-koeln.de

${ }^{b}$ Université Lyon 1, IRCELYON, CNRS-UMR 5256, 2 Avenue A. Einstein, 69626 Villeurbanne, France. E-mail: shashank.mishra@ircelyon.univ-lyon1.fr

$\dagger$ Electronic supplementary information (ESI) available. CCDC 2104958-2104960. For ESI and crystallographic data in CIF or other electronic format see DOI: 10.1039/d1dt02964a
}

phases encountered frequently during their synthesis. ${ }^{9} \mathrm{SnE}$, where tin has the +II oxidation state, has an orthorhombic crystal structure, built out of wrinkled honeycomb layers of Sn and $\mathrm{S} / \mathrm{Se}$ having covalent interlayer bonds and weak vdW forces between single layers. ${ }^{7} \mathrm{SnE}$, which has its bandgap located between those of Si and GaAs, exhibits both the p- and n-type conduction depending on the concentration of tin. ${ }^{12-14}$ Therefore, SnE can be potentially used as a solar absorber in thin film solar cells and near-infrared detectors ${ }^{3,15,16}$ and as a photovoltaic material. ${ }^{2,17}$ On the other hand, tin dichalcogenides $\mathrm{SnE}_{2}\left(\mathrm{SnS}_{2} / \mathrm{SnSe}_{2}\right)$ are n-type semiconductors with an indirect band gap of $2.1 \mathrm{eV} / 1.1 \mathrm{eV}$ and a direct band gap of 2.8 $\mathrm{eV} / 1.8 \mathrm{eV}^{7,9,18}$ They have a hexagonal $\mathrm{CdI}_{2}$-type crystal structure consisting of an E-Sn-E triple layers, where the atomic layers are held together by weak van der Waals forces of attraction and have been extensively studied in their bulk form in the past. ${ }^{19}$ Recently, single and few-layered $\mathrm{SnE}_{2}$ have been employed in several applications including water splitting, ${ }^{20-22}$ field-effect transistors ${ }^{23,24}$ and gas sensing. ${ }^{25,26}$

The chemical, physical and electronic properties of these materials are often governed by the synthetic methods employed to prepare them. In general, the soft chemical routes using well-characterized single source precursors (SSPs) for the synthesis of nanomaterials have numerous advantages, like tight control over the phase, morphology and stoichiometry. ${ }^{27-29}$ Among these routes, the chemical solution deposition methods are attractive because they offer high-yield and substrate-free synthesis of nanomaterials with tunable nanostructures at much lower temperatures. ${ }^{30,31}$ Although a 
huge range of different $\mathrm{SnE}$ and $\mathrm{SnE}_{2}$ nanostructures have been synthesized in the solution phase, ${ }^{32,33}$ very few $2 \mathrm{D}$ tin chalcogenide nanostructures have been prepared from SSPs. Different nanostructured $\mathrm{SnE}$ and $\mathrm{SnE}_{2}$ materials have been synthesized using solution based SSP approaches, like SnSe nanorods, ${ }^{28}$ SnSe nanowires, ${ }^{34,35}$ SnSe needles, ${ }^{36} \mathrm{SnS} / \mathrm{Se}$ nanoparticles $^{37}$ and few-layer $\mathrm{SnSe} / \mathrm{SnSe}_{2}$ nanosheets. ${ }^{28,36}$ Despite these successes, the phase-controlled synthesis of $2 \mathrm{D}$ tin sulfide and selenide nanostructures remains a challenge. Based on the excellent properties of $2 \mathrm{D}$ layered crystal structures and their unique mechanical flexibility, synthesizing 2D tin chalcogenide nanostructures is of great importance.

The above literature survey indicates that the chemical routes to $2 \mathrm{D} \mathrm{SnE}$ and $\mathrm{SnE}_{2}$ from a single source remain underdeveloped and there is a scope for the development of wellcharacterized molecular precursors for these materials. ${ }^{38}$ In this study, we report a 'bottom-up' approach for the synthesis of $\mathrm{SnE}$ and $\mathrm{SnE}_{2}$ nanostructures using different tin-based sulfur and selenide precursors. We employed $N$-alkyl-diethanethiolamine and $N, N$-dimethylselenourea ligands (Scheme 1) because of their versatile coordination behavior and ability to

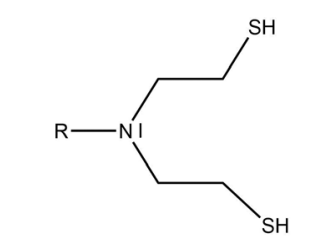

$\mathrm{R}=\mathrm{Me} ; \mathrm{N}$-methyldiethanthiolamine $\left(\right.$ mdetaH $\left._{2}\right)$ $\mathrm{R}=\mathrm{Et} ; \mathrm{N}$-ethyldiethanthiolamine $\left(\mathrm{edetaH}_{2}\right)$

Scheme 1 The sulfur- and selenium-containing ligands used in this study. transfer chalcogenide atoms easily to metal centers to obtain metal chalcogenide nanomaterials. ${ }^{39,40}$

\section{Results and discussion}

2.1. Synthesis and characterization of $\mathrm{Sn}$ (II) and $\mathrm{Sn}(\mathrm{IV})$ complexes with $\mathrm{N}$-alkyl-diethanethiolamine ligands as precursors to tin sulfide nanoaprticles

Tridentate chelating dithiol ligands $\mathrm{N}$-alkyl-diethanethiolamine $\mathrm{RN}\left(\mathrm{C}_{2} \mathrm{H}_{4} \mathrm{SH}\right)_{2}$ were used in the synthesis of stable metal complexes enabling the control of the coordination sphere of the coordinated metal center. ${ }^{39,41}$ The limited commercial availability and high price of these ligand types triggered us to the synthetic pathways of SNS type ligands starting from their dialcohol-derivatives with thiourea as a sulfur-source. ${ }^{39,41,42}$

The tin reagents $\left[\mathrm{Sn}\left(\mathrm{N}\left(\mathrm{SiMe}_{3}\right)_{2}\right)_{2}\right]^{43}$ and $\left[\mathrm{Sn}\left(\mathrm{O}^{t} \mathrm{Bu}\right)_{4}\right]{ }^{44}$ presynthesized as described in the literature, reacted with the dithiol-ligands $\mathrm{RN}\left(\mathrm{C}_{2} \mathrm{H}_{4} \mathrm{SH}\right)_{2}(\mathrm{R}=\mathrm{Me}, \mathrm{Et})$ in toluene to form $\mathrm{Sn}(\mathrm{II})$ and $\mathrm{Sn}(\mathrm{IV})$ complexes $\left[\mathrm{Sn}\left\{\left(\mathrm{SC}_{2} \mathrm{H}_{4}\right)_{2} \mathrm{NMe}\right\}\right]$ (1), [Sn $\left.\left\{\left(\mathrm{SC}_{2} \mathrm{H}_{4}\right)_{2} \mathrm{NEt}\right\}\right] \quad(2), \quad\left[\mathrm{Sn}\left\{\left(\mathrm{SC}_{2} \mathrm{H}_{4}\right)_{2} \mathrm{NMe}\right\}_{2}\right] \quad(3)$ and $\quad[\mathrm{Sn}$ $\left.\left\{\left(\mathrm{SC}_{2} \mathrm{H}_{4}\right)_{2} \mathrm{NEt}\right\}_{2}\right]$ (4) (Scheme 2). In these complexes, the dianionic chelating ligand $\mathrm{RN}\left(\mathrm{C}_{2} \mathrm{H}_{4} \mathrm{~S}\right)_{2}{ }^{2-}(\mathrm{R}=\mathrm{Me}, \mathrm{Et})$ coordinates to the tin center in a tridentate fashion, yielding air-stable complexes. The dark orange solution of $\left[\mathrm{Sn}\left(\mathrm{N}\left(\mathrm{SiMe}_{3}\right)_{2}\right)_{2}\right]$ in toluene instantaneously discolored on adding one equivalent of the mdeta $_{2}$ or $e$ detaH $H_{2}$ ligand, leading to precipitation of colorless and pale yellow colored solids, later identified as [Sn $\left.\left\{\left(\mathrm{SC}_{2} \mathrm{H}_{4}\right)_{2} \mathrm{NMe}\right\}\right]$ (1) and $\left[\mathrm{Sn}\left\{\left(\mathrm{SC}_{2} \mathrm{H}_{4}\right)_{2} \mathrm{NEt}\right\}\right]$ (2), respectively. Mass analysis confirmed the successful synthesis of tin(II) complexes 1 and 2 with observed molecular peaks of $269 \mathrm{~m} / \mathrm{z}$ and $283 \mathrm{~m} / \mathrm{z}$, respectively. Additional NMR analysis of both complexes showed highly solvent-dependent signal splitting with a total of 11 proton signals for 1 and 13 protons signals

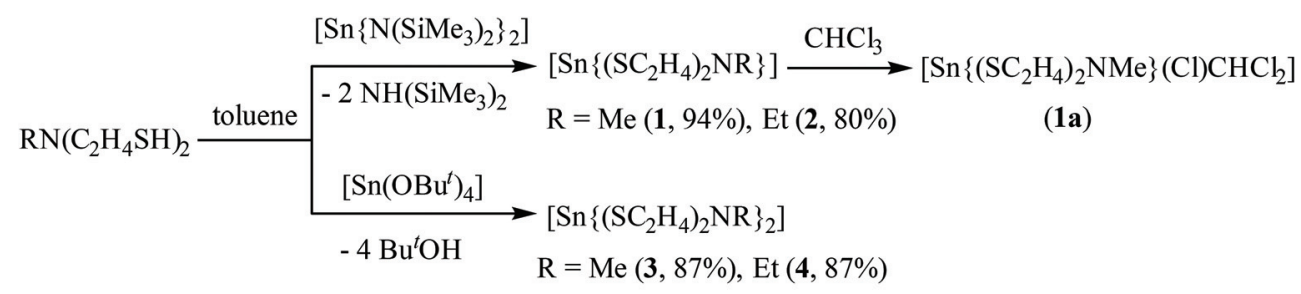

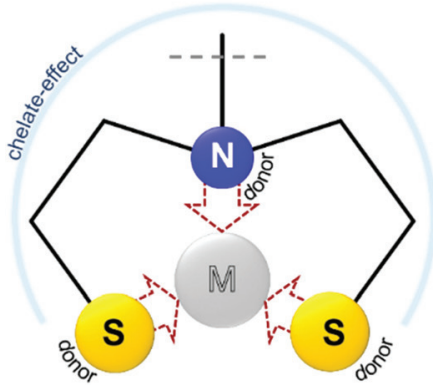

Scheme 2 Synthesis of $\mathrm{Sn}(\mathrm{II})$ and $\mathrm{Sn}(\mathrm{IV})$ complexes 1-4 (above) and the coordination mode of the ligand $\mathrm{N}$-alkyl-diethanethiolamine $\mathrm{RN}\left(\mathrm{C}_{2} \mathrm{H}_{4} \mathrm{SH}\right)_{2}$ in these complexes (below). 
for 2 in less polar solvents. Proton NMR measurements of $\mathbf{1}$ in $\mathrm{C}_{6} \mathrm{D}_{6}$ showed five inequivalent proton signals with an integral ratio of $3: 2: 2: 2: 2$, displaying each ethanethiol $\mathrm{CH}_{2}$-protons in an integrative reaction of 2 . The two high-field shifted proton signals belong to the $\mathrm{CH}_{2}$ group next to the sulfur and the two low-field shifted protons were identified as $\mathrm{CH}_{2}$ protons located next to the bridging nitrogen. The methyl group located at the nitrogen was appeared with an integral ratio of 3 . This signal splitting reveals a relatively rigid structure in $\mathrm{C}_{6} \mathrm{D}_{6}$, whereas three non-equivalent proton signals with an integral ratio of $3: 4: 4$ were detected in DMSO-d6. Separation of single $\mathrm{CH}_{2}$ signals for each ethanethiol chain was not possible. The proton signals at the lower field were identified as $\mathrm{CH}_{2}$ protons next to the sulfur of both ethanethiol chains and the highfield shifted signals belong to $\mathrm{CH}_{2}$ protons located at the bridging nitrogen. For both measurements, three inequivalent carbon signals correlating with the expected $\mathrm{CH}_{2}$ and $\mathrm{CH}_{3}$ protons were observed. Two carbon peaks with different chemical shifts but the same signal orientation in the ${ }^{13} \mathrm{C}$ APT spectrum correlate with the ethanethiol chains. The highfield shifted signal correlates with the protons next to the sulfur, whereas the lowfield shifted signals belong to the $\mathrm{CH}_{2}$ protons located next to the nitrogen. The carbon signal with a different orientation was clearly identified as the $\mathrm{CH}_{3}$ signal. Proton NMR analysis of 2 displays four nonequivalent signals with an integral ratio of $2: 4: 4: 3$ in DMSOd6. Four different carbon signals detected in the ${ }^{13} \mathrm{C}$ APT spectrum correlated with the expected $\mathrm{CH}_{2}$ and $\mathrm{CH}_{3}$ protons. Three C peaks with equal signal orientation were detected as $\mathrm{CH}_{2}$ signals, whereas one opposite orientated $\mathrm{C}$ signal displayed the $\mathrm{CH}_{3}$ function of the ethyl group at the bridging nitrogen, confirming the tridentate coordination of the edeta ligand. The ${ }^{119}$ Sn NMR spectrum of 1 , recorded in DMSO-d6, showed a peak at $\delta 124 \mathrm{ppm}$, which is typical of a 3-coordinated tin(II) center. ${ }^{45}$ These observed NMR analytics are in good agreement with the reported data of Tzschach et al. ${ }^{46}$ Both synthesized compounds show long term stability only in the solid state.

Crystallization of $\mathbf{1}$ in solvents like chloroform or pyridine afforded in oxidative addition products, $\left[\mathrm{Sn}\left\{\left(\mathrm{SC}_{2} \mathrm{H}_{4}\right)_{2} \mathrm{NMe}\right\}(\mathrm{Cl})\right.$ $\left.\mathrm{CHCl}_{2}\right]$ (1a) and $\left[\mathrm{Sn}\left\{\left(\mathrm{SC}_{2} \mathrm{H}_{4}\right)_{2} \mathrm{NMe}\right\}_{2}\right]$ (3), respectively, resulting from the coordination of a $\mathrm{CHCl}_{2}{ }^{-}$unit and a single chloride $\mathrm{Cl}^{-}$coming from the solvent in 1a or the coordination of a second tridentate mdeta ligand to the tin center in 3 . The ${ }^{1} \mathrm{H}$ NMR analysis of $1 \mathrm{a}$ in $\mathrm{CDCl}_{3}$ showed a total of 12 protons in an integral ratio of $1: 3: 2: 2: 4$ as compared to 11 protons observed in 1. Clearly, the additional proton in 1a belongs to the $\mathrm{CHCl}_{2}{ }^{-}$unit. The oxidation state as well as the coordination number of the tin center in synthesized complexes can be easily identified from the ${ }^{119} \mathrm{Sn}$ NMR spectrum as shown in Fig. 1a, c and $\mathrm{d}$. While the tridentate coordination of one chelating mdeta ligand to the tin(II) center ensures that one coordination halfsphere of the formed complex is shielded, the other coordination half-sphere is more deshielded, leaving the tin(II) center susceptible to oxidative addition (Fig. 1b). The ${ }^{119}$ Sn NMR spectrum of 1a displayed a signal at $\delta-134 \mathrm{ppm}$, which is consistent with a tin(Iv) center in a pentagonal coordination ${ }^{47}$ (Fig. 1d). On the other hand, the ${ }^{119} \mathrm{Sn}$ NMR spectrum of $\left[\mathrm{Sn}\left\{\left(\mathrm{SC}_{2} \mathrm{H}_{4}\right)_{2} \mathrm{NMe}_{2}\right]\right.$ (3) showed a peak at $\delta-183 \mathrm{ppm}$, which corresponds well to a six-coordinated tin(Iv) center (Fig. 1c). Compound 3 has been directly synthesized following a different synthetic route, and will be discussed later. Comparable oxidation reactions have been observed in coordination solvents for compound 2 . Therefore, the main characterisation in solution has been performed in $\mathrm{C}_{6} \mathrm{D}_{6}$ or DMSO-d6.

The structure of $\left[\mathrm{Sn}\left\{\left(\mathrm{SC}_{2} \mathrm{H}_{4}\right)_{2} \mathrm{NMe}\right\}(\mathrm{Cl}) \mathrm{CHCl}_{2}\right]$ 1a was solved by single crystal X-ray studies, which showed a five-fold coordi- a)

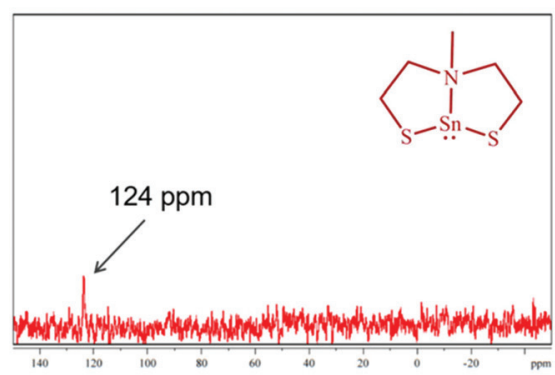

c)

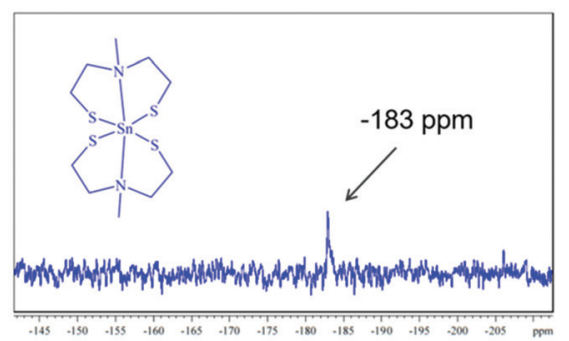

b)
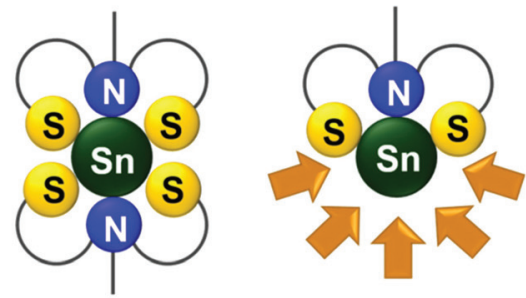

d)

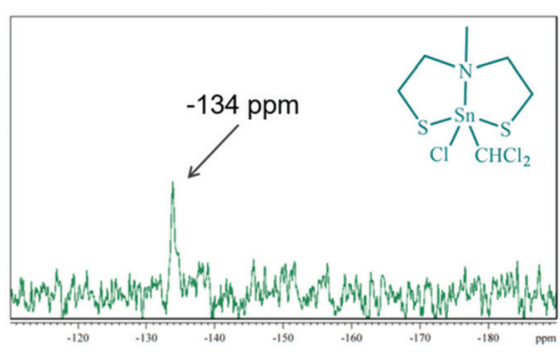

Fig. 1 Comparison of ${ }^{119} \mathrm{Sn} N M R$ spectra of complexes $\left[\mathrm{Sn}\left\{\left(\mathrm{SC}_{2} \mathrm{H}_{4}\right)_{2} \mathrm{NMe}\right\}\right] 1$ (a), $\left.\left[\mathrm{Sn}_{2}\left(\mathrm{SC}_{2} \mathrm{H}_{4}\right)_{2} \mathrm{NMe}\right\}_{2}\right] 3$ (c) and $\left.\left[\mathrm{Sn}_{2}\left(\mathrm{SC}_{2} \mathrm{H}_{4}\right)_{2} \mathrm{NMe}\right\} \mathrm{ClCHCl}{ }_{2}\right] 1 \mathrm{a}(\mathrm{d})$. Schematic diagram showing $\mathrm{Sn}^{2+}$ and $\mathrm{Sn}^{4+}$ coordination spheres with one or two tridentate ligands (b). 
nation of the tin center in a distorted trigonal bipyramidal environment (Fig. 2). The oxidative addition of chloroform to complex 1 resulting in complex $\mathbf{1 a}$ has been reported before, but no crystal structure was described. ${ }^{45,48}$ A triangular plane is formed by both sulfur atoms from the tridentate mdeta ligand and the carbon atom from the $\mathrm{CHCl}_{2}{ }^{-}$unit. The axial positions of the bipyramid are occupied by the bridging nitrogen and the coordinated chloride. The C6-Sn1-Cl3 angle of around $92^{\circ}$ is close to the ideal trigonal bipyramidal angle of $90^{\circ}$. Due to the repulsing effect, both chlorides from the $\mathrm{CHCl}_{2}{ }^{-}$unit are orientated away from the metal center. Therefore, the N1-Sn1-C6 angle $\left(\sim 96^{\circ}\right)$ is slightly more distorted. Angles of $\mathrm{S} 1-\mathrm{Sn} 1-\mathrm{Cl} 3$ and $\mathrm{S} 2-\mathrm{Sn} 1-\mathrm{Cl} 3$, around $92^{\circ}$ and $94^{\circ}$, respectively, are slightly smaller than the literature values in the related complexes $\left(98-121^{\circ}\right) .{ }^{49}$ The tridentate coordination of the ligand is comparable to the previously reported coordination motive of $\mathrm{MeN}\left(\mathrm{C}_{2} \mathrm{H}_{4} \mathrm{SH}\right)_{2} \cdot{ }^{39}$ The S1-Sn-S2 angle in the equatorial plane is around $121^{\circ}$, which is in good agreement with the literature data. ${ }^{50}$ The Sn1-S1/2 (2.37-2.38 ̊) and $\mathrm{Sn} 1-\mathrm{Cl} 3(2.40 \AA)$ bond distances also compare well with the literature..$^{50,51}$

The reaction of $\left[\mathrm{Sn}\left(\mathrm{O}^{t} \mathrm{Bu}\right)_{4}\right]$ with two equivalents of each ligand $\mathrm{mdetaH}_{2}$ and edetaH $\mathrm{H}_{2}$ resulted in the formation of colorless precipitates. $\operatorname{Bis}\left(\left(2,2^{\prime}\right.\right.$-(methylazanediyl)bis(ethane-1-thiolate)) $\operatorname{tin}(\mathrm{rv})\left[\mathrm{Sn}\left\{\left(\mathrm{SC}_{2} \mathrm{H}_{4}\right)_{2} \mathrm{NMe}\right\}_{2}\right] 3$ and bis((2,2'-(ethylazanediyl) bis(ethane-1-thiolate)) tin(Iv) $\left.\left[\mathrm{Sn}_{\{}\left\{\mathrm{SC}_{2} \mathrm{H}_{4}\right)_{2} \mathrm{NEt}\right\}_{2}\right] 4$ were isolated as colorless crystals from the reaction media and washed several times with $n$-heptane and toluene, followed by drying under reduced pressure. The NMR spectra in solution showed a total of 22 protons for 3 with three non-equivalent signals in an integral ratio of $6: 8: 8$ and 26 protons for 4 with four inequivalent signals in an integral ratio of $6: 8: 8: 4$. For both complexes, the two broad low-field shifted signals referred to the $\mathrm{CH}_{2}$ protons, which was confirmed by $2 \mathrm{D} \mathrm{H}, \mathrm{C}$ NMR measurements. These signals result from the fluctuation of the ligands in solution, indicating that the structure in solu-

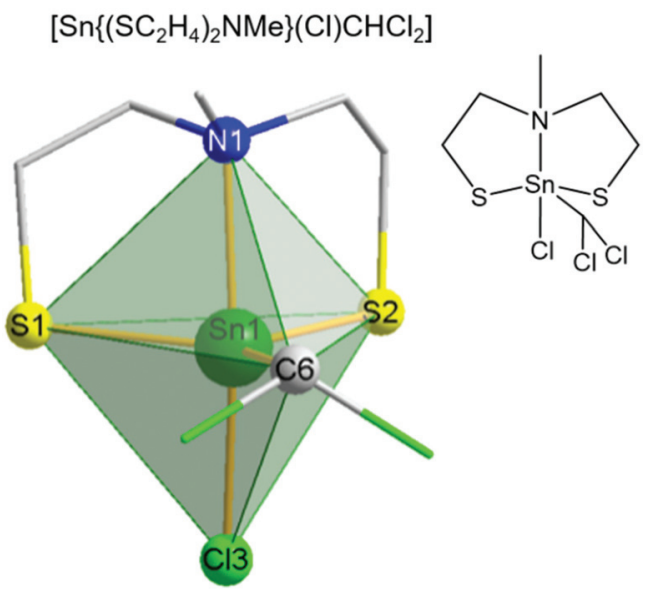

Fig. 2 Molecular structure of $\left[\mathrm{Sn}\left\{\left(\mathrm{SC}_{2} \mathrm{H}_{4}\right)_{2} \mathrm{NMe}\right\}(\mathrm{Cl}) \mathrm{CHCl}_{2}\right]$ 1a. A distorted trigonal-bipyramidal geometry is confirmed by a factor $\tau$ of $0.79 .{ }^{51 b}$ tion is not rigid and therefore no distinction between each coordinated ligand was observable. Therefore, only two chemically non-equivalent carbon signals correlating with the $\mathrm{CH}_{2}$ proton signals were detected. The sharp singlet at the higher field $(\delta 2.5 \mathrm{ppm})$ corresponds to both the methyl functions at each bridging nitrogen for compound 3, confirmed by 2D H,C correlation NMR spectra. The clear triplet at high field $(\delta$ $1.1 \mathrm{ppm}$ ) was clearly identified as $\mathrm{CH}_{3}$ protons from the ethylgroup located at the bridging nitrogen of complex 4 by 2D H,C correlation spectra. These NMR data are in good agreement with the structural investigations in solution performed by Tzschach et $a .^{46}$ To the best of our knowledge, to date no crystal structure has been reported for compounds 3 and $\mathbf{4}$. Therefore, attempts were made to grow suitable crystals of 3 and 4 for single crystal X-ray diffraction studies. The molecular structures of both tin(Iv) complexes $\left[\mathrm{Sn}\left\{\left(\mathrm{SC}_{2} \mathrm{H}_{4}\right)_{2} \mathrm{NR}\right\}_{2}\right](\mathrm{R}=\mathrm{Me}$ (3), Et (4)) present the tin center in a distorted octahedral environment (Fig. 3a and b). Two of each dianionic ligands (mdeta and edeta) coordinate the metal center in a tridentate fashion, which consequently resulted in an oxidation state of $+\mathrm{IV}$ of the tin centers. Complex $\mathbf{3}$ is an isotype to the already reported molecular structures of $\left[\mathrm{M}\left\{\mathrm{SS}_{2} \mathrm{H}_{4}\right)_{2} \mathrm{NMe}_{2}\right](\mathrm{M}=$ $\left.\mathrm{Mo}^{\mathrm{IV}}, \mathrm{W}^{\mathrm{IV}}\right)$ and crystallizes in the triclinic space group $P \overline{1},{ }^{39}$ whereas complex $\mathbf{4}$ crystalizes in the monoclinic space group $P 21 / n$. The coordination sphere around both Sn centers is completed by the tridentate coordination of two 2,2'-(alkylazanediyl)bis(ethane-1-thiolate) ligands (mdeta and edeta), forming two triangular planes above and underneath the metal center. Each of these triangular planes is built out of two sulfur atoms and the bridging nitrogen atom (plane A, S1N1-S2; plane B, S3-N2-S4 for 3 and 4, Fig. 3c) from each coordinated ligand. Planes A and B were twisted against each other by an angle of $c a .65^{\circ}$ for 3 and $67^{\circ}$ for 4 , possibly due to the repulsive effect of the alkyl groups at each nitrogen atom and the spatial requirements of the lone pairs present on the sulfur atoms in the ligand backbone. In the molecular structure of both distorted octahedral tin complexes 3 and 4 , the sulfur-metal bonds varied over the range of 2.43-2.47 $\AA$, which are consistent with the values reported for other chelating dithiol and nitrogen-dithiol metal complexes (2.39-2.56 ̊). The Sn-N bond lengths $(2.52-2.57 \AA)$ are a little elongated as compared to literature data $(2.37-2.42 \AA)^{49,52,53}$ The S-Sn-S angles in each coordinated ligand were $110^{\circ}$ and $112^{\circ}$ for 3 and $\mathbf{4}$, respectively, which is in agreement with the reported values. ${ }^{49,52}$ As found for the isotype structures of tungsten and molybdenum, ${ }^{39}$ each tridentate coordinated ligand formed two five-membered rings with the tin center in 3 and 4 [(1) Sn1-S1-C1-C2-N1), (2) Sn1-S2-C3-C4-N1, Fig. 3d].

The decomposition behavior of complexes $\mathbf{1}$ and $\mathbf{3}$ was investigated by thermogravimetric measurements and simple thermal decomposition experiments under ambient conditions and lower temperatures, meaning controlled decomposition on a heating plate at a maximum of $500{ }^{\circ} \mathrm{C}$. The TG-DSC measurements of 1 up to $500{ }^{\circ} \mathrm{C}$ show a one-step decomposition (Fig. 4a). The decomposition process starts at around $210{ }^{\circ} \mathrm{C}$ and lasts until $300{ }^{\circ} \mathrm{C}$. The total mass loss of around 
a)

$\left[\mathrm{Sn}\left\{\left(\mathrm{SC}_{2} \mathrm{H}_{4}\right)_{2} \mathrm{NMe}\right\}_{2}\right]$

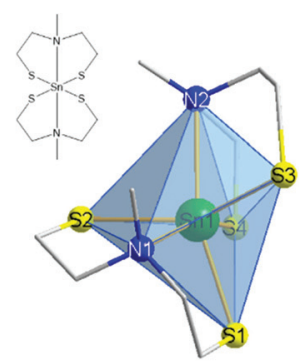

b)

$\left[\mathrm{Sn}\left\{\left(\mathrm{SC}_{2} \mathrm{H}_{4}\right)_{2} \mathrm{NEt}\right\}_{2}\right]$

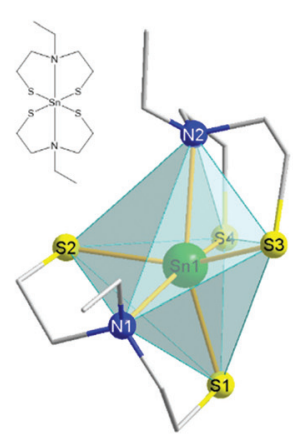

c)

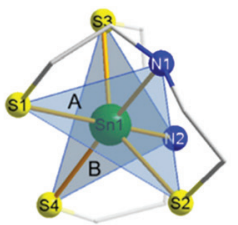

d)

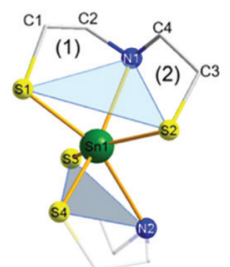

Fig. 3 Molecular structures of $\left[\mathrm{Sn}\left\{\left(\mathrm{SC}_{2} \mathrm{H}_{4}\right)_{2} \mathrm{NMe}\right\}_{2}\right] 3$ (a) and $\left[\mathrm{Sn}\left\{\left(\mathrm{SC}_{2} \mathrm{H}_{4}\right)_{2} \mathrm{NEt}\right\}_{2}\right] 4$ (b). Polyhedral structures showing two twisted trigonal planes ( $A$ and $B$ ) above and underneath the tin center (c). Each plane was formed by a tridentate coordinated ligand (d). Selected cell parameters as well as selected bond lengths and angles for 3, 4 and 1 a are presented in the ESI (Tables S1 and S2†).
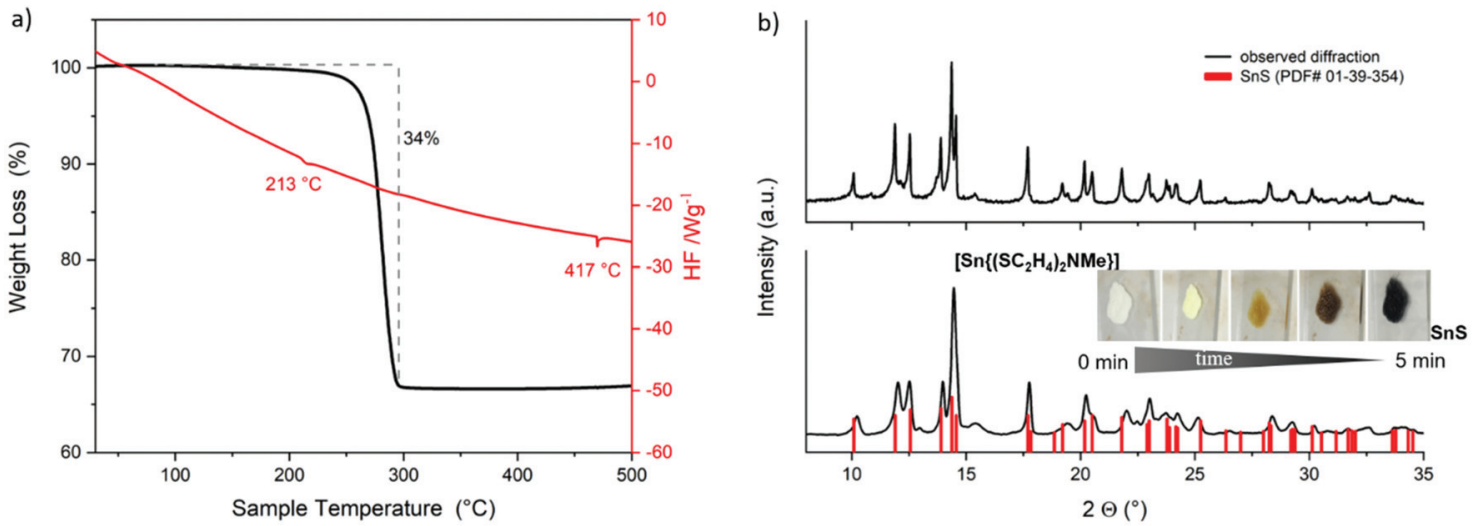

Fig. 4 TG-DSC measurements of [Sn $\left.\left\{\left(\mathrm{SC}_{2} \mathrm{H}_{4}\right)_{2} \mathrm{NMe}\right\}\right] 1$ (a), XRD pattern of the TGA residue (b, top), thermal decomposition of 1 on a heating plate (inset $b$, bottom), and XRD pattern of the remaining residue at the end of decomposition ( $b$, bottom).

$33 \%$ did not fit completely to the expected mass of $\mathrm{SnS}$ (150.8 $\left.\mathrm{g} \mathrm{mol}^{-1}\right)$. However, XRD analysis of the nearly black colored residue confirmed the formation of crystalline $\mathrm{SnS}$ (Fig. 4b, top, PDF\# 01-39-354). Fast thermal decomposition under ambient conditions on a heating plate was indicated by the fast color change of $\mathbf{1}$ (Fig. $4 \mathrm{~b}$, bottom (inset)). The remaining black product was analyzed by XRD measurements, which confirmed the formation of the desired $\mathrm{SnS}$ crystal phase (Fig. 4b, bottom). Investigations in solution and in the solid state of $\mathbf{1}$ as well as the suitable thermal stability and clean decomposition to the target material clearly show the potential application of this molecular compound as a suitable SSP for SnS material preparation. Moreover, the stability of $\mathbf{1}$ in solution offers a potential application for the target catalytic oxidative addition reactions. ${ }^{54-56}$

In contrast to the single-step thermal decomposition of Sn(II) compound 1, TG-DSC investigations of the Sn(Iv) compound 3 up to $800{ }^{\circ} \mathrm{C}$ showed a multistep decomposition with a mass loss of $64 \%$, which corresponds to the mass of $\mathrm{SnS}$
(150.8 $\mathrm{g} \mathrm{mol}^{-1}$ ) (Fig. 5b) and have been confirmed by XRD (Fig. 5d, bottom, PDF\# 01-39-354). Repeated TG-DSC measurements at lower temperatures up to $600{ }^{\circ} \mathrm{C}$ (Fig. 5a) showed again a multistep decomposition with a total mass loss of $60 \%$ corresponding to the mass of $\mathrm{Sn}_{2} \mathrm{~S}_{3}\left(166.8 \mathrm{~g} \mathrm{~mol}^{-1}\right)$, a mixed $\mathrm{Sn}(\mathrm{II})-\mathrm{Sn}$ (Iv) sulfide crystal phase, as confirmed by XRD measurements (Fig. 5c, middle, PDF\# 01-30-1377). Further reduction of decomposition temperatures to $500{ }^{\circ} \mathrm{C}$ provided the target $\mathrm{SnS}_{2}$ phase. Fast thermal decomposition of 3 under ambient conditions at around $500{ }^{\circ} \mathrm{C}$ led to an immediate color change (Fig. 5c). The obtained nearly black residue was analyzed by XRD measurement to confirm the formation of crystalline $\mathrm{SnS}_{2}$ (PDF\# 01-21-1231, Fig. 5d, top) with an estimation of around $75 \%$ of amorphous phase formation.

It is remarkable that the synthesized molecular tin precursors 1 and $\mathbf{3}$ decompose neatly under ambient conditions to the corresponding pure sulfide materials (instead of giving oxidized products). These outstanding properties and behavior of 1 and 3 originate from the extraordinary control of the coordi- 
a)

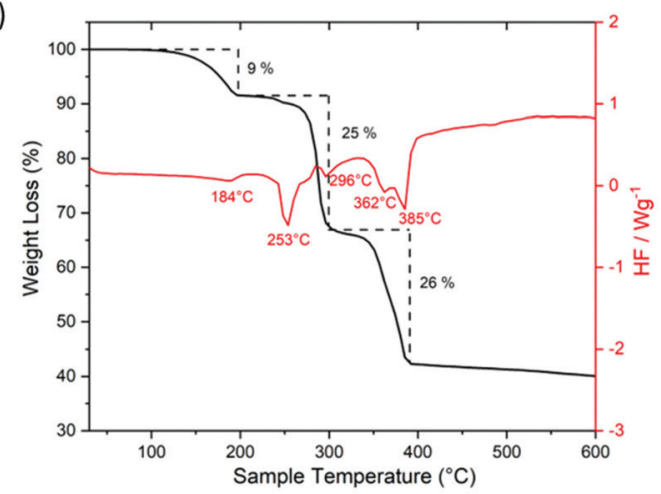

b)

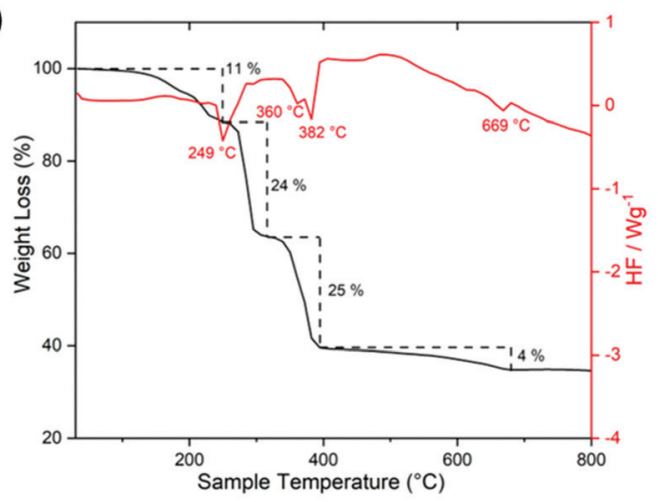

c)

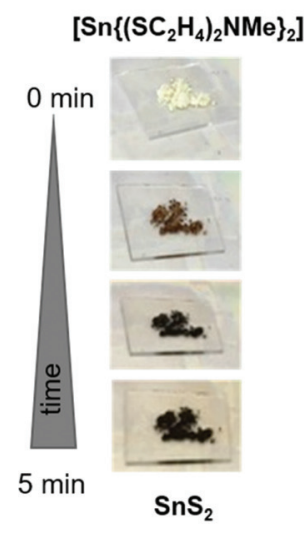

d)

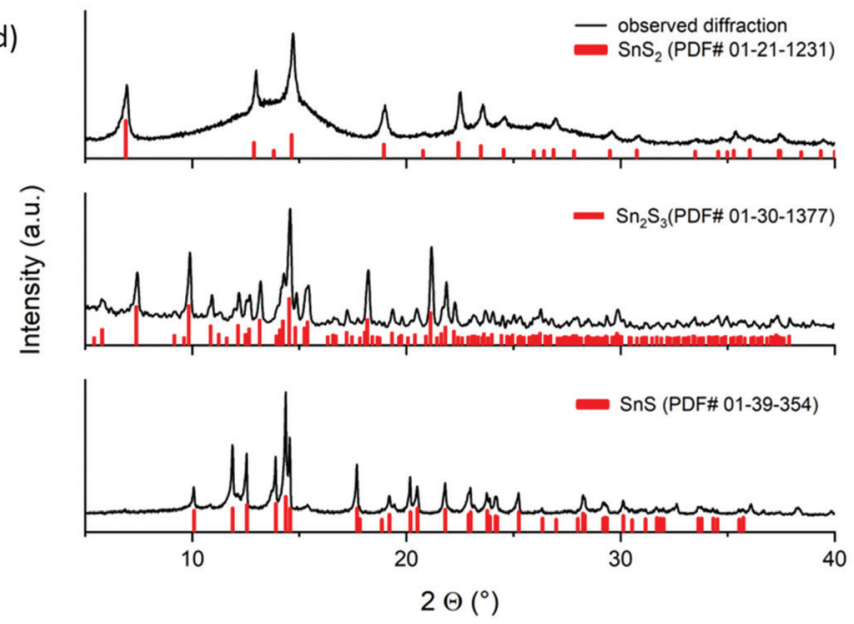

Fig. 5 TG-DSC measurements at different temperatures (a, b), decomposition under ambient conditions on a heating plate (c) of [Sn $\left.\left\{\left(\mathrm{SC}_{2} \mathrm{H}_{4}\right)_{2} \mathrm{NMe}\right\}_{2}\right] 3$. XRD measurement of the formed tin sulfide phase (d). The fraction of the amorphous phase was estimated by correlating the contributions from crystalline phases and an amorphous halo to the overall peak area after background subtraction to $75 \%$.

nation sphere by using tridentate chelating dithiol ligands. Furthermore, investigations of the isolated different crystal phases $\left(\mathrm{SnS}_{2}, \mathrm{Sn}_{2} \mathrm{~S}_{3}, \mathrm{SnS}\right)$ have been performed by the thermal decomposition of 3 . The results regarding their physical properties, special coordination polyhedra and thermal behavior have been compared with the literature. Fig. 6 shows the three stable tin sulfide crystal phases $\mathrm{SnE}, \mathrm{Sn}_{2} \mathrm{E}_{3}$ and $\mathrm{SnE}_{2}$, their elemental composition as well as their stacking of single tin chalcogenide phases.

Tin has two stable oxidation states Sn(II) and Sn(IV), where their transition is subtle. While $\mathrm{SnE}_{2}$ and $\mathrm{SnE}$ have one single oxidation state for tin, $\mathrm{Sn}_{2} \mathrm{E}_{3}$ is a multivalent compound containing tin in both stable oxidation states, $\mathrm{Sn}$ (II) and $\mathrm{Sn}(\mathrm{IV})$. Resulting from the lone pair located at the tin(II) center, SnE forms trigonal pyramids, whereas tin(Iv) forms edge-linked octahedra, forming 2D structures for both cases. The $\mathrm{Sn}_{2} \mathrm{E}_{3}$ phase containing equal amounts of $\mathrm{Sn}$ (II) and $\mathrm{Sn}$ (IV) forms chains of alternating $\mathrm{Sn}$ (II)-tetrahedron and $\mathrm{Sn}$ (Iv)octahedron. ${ }^{9,57}$ The formation of a specific tin sulfide/selenide phase is temperature-dependent, as clearly demonstrated by the thermal decomposition of the molecular compound 3 . Thermodynamically, the most stable phase is SnS, followed by $\mathrm{Sn}_{2} \mathrm{E}_{3}$, whereas $\mathrm{SnE}_{2}$ represents the most delicate crystal phase. The formation of the desired tin sulfide phases out of molecular precursor 3 can be set by careful thermal treatment.

Microwave-assisted solvothermal decomposition of $\mathbf{1}$ for $5 \mathrm{~min}$ at $200 \mathrm{~W}$ in NMP ( $\mathrm{N}$-methyl-2-pyrrolidone) resulted in a flake-like structured material (Fig. S1†), whereas similar decomposition of 3 for $7 \mathrm{~min}$ afforded spherical tin sulfide particles (Fig. 7b). The formed nanostructured materials were washed several times with ethanol using the centrifugation method and were further characterized using SEM, TEM (Fig. 7) and XPS analyses (Fig. S2 $\dagger$ ).

\subsection{Synthesis and characterization of $\mathrm{Sn}$ (II) and $\mathrm{Sn}$ (Iv) complexes with a $N, N$-dimethylselenourea ligand and their conversion to nanometric tin selenides}

As compared to nanometric metal-sulfides, the precursor chemistry of metal selenide nanomaterials remain less developed, mainly because of the limited commercial availability of selenide ligands. ${ }^{61}$ We have used previously dialkylselenides $\mathrm{R}_{2} \mathrm{Se}$ as versatile ligands that afford metal selenide nanoparticles under mild conditions and in high yield. ${ }^{31}$ However, the limited commercial availability and very high price of these ligands, particularly of ${ }^{t} \mathrm{Bu}_{2} \mathrm{Se}$ which is the most reactive reagent in this series, are the major constraints. Very recently, 


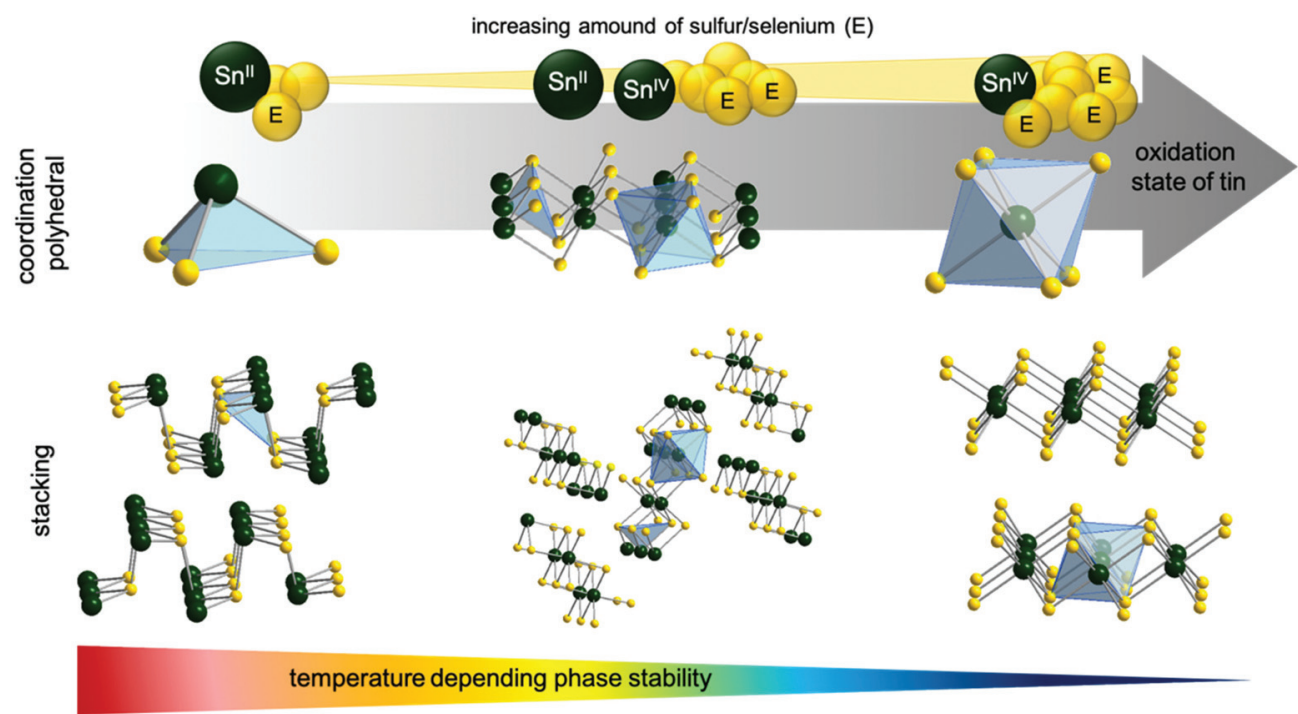

Fig. 6 Temperature dependent phase stability and coordination polyhedra of tin chalcogenides.
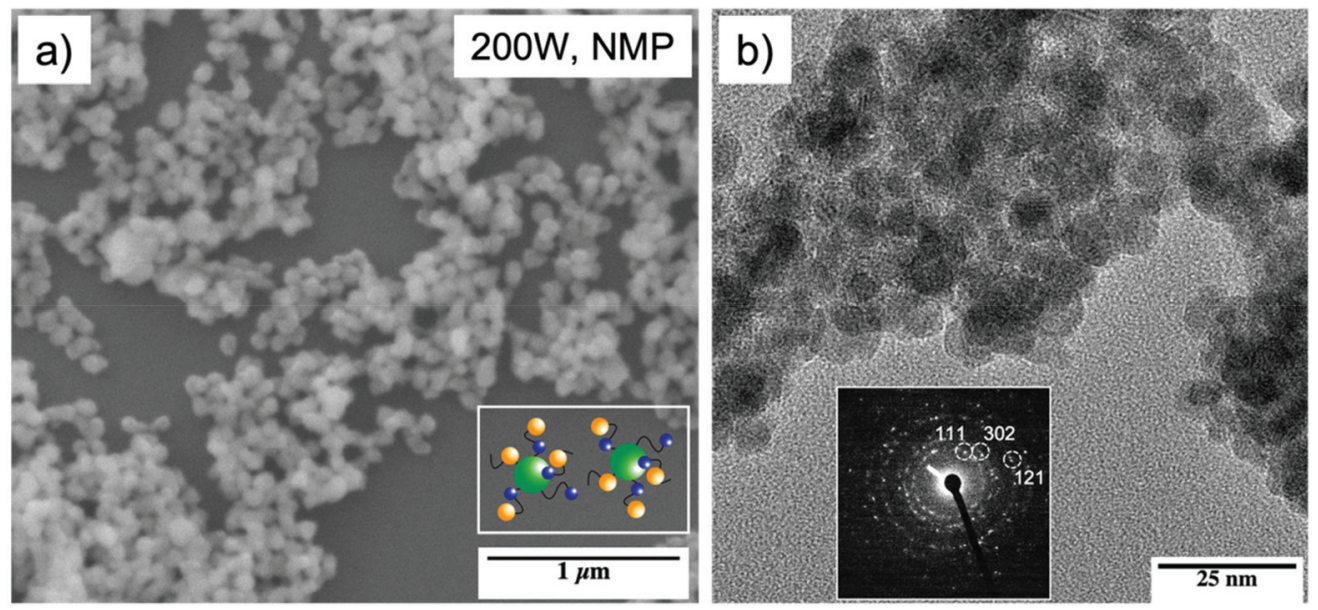

Fig. 7 SEM image of tin sulfide particles obtained by the microwave-assisted decomposition of $\left.\left[\mathrm{Sn}_{2}\left(\mathrm{SC}_{2} \mathrm{H}_{4}\right)_{2} \mathrm{NMe}\right\}_{2}\right] 3$ (inset: scheme of particles with capping ligands) (a), TEM images of 3 and the associated FFT (shown as inset) (b) constant with orthorhombic $\mathrm{Sn}_{2} \mathrm{~S}_{3}$ (PDF \# 01-072-). XPS measurements of the microwave assisted decomposition of 3 (Fig. S2 $\dagger$ ) showed the partial reduction of the Sn(IV) center, resulting in a mixed product formation of $\mathrm{SnS}_{2}$ and $\mathrm{Sn}_{2} \mathrm{~S}_{3}$. This was reinforced by measuring the interlayer distance calculated from FFT measurement of TEM analysis amounted to $2.7 \AA$ for (302), $3.4 \AA$ for (111) and $1.8 \AA$ for (121) (b), which is in good agreement with the literature reported d-d spacing of $\mathrm{Sn}_{2} \mathrm{~S}_{3} .{ }^{58-60}$ In conclusion, the chosen decomposition parameters showed the partial reduction of the Sn(IV) center to Sn(II), resulting in mixed tin sulfide phases. Additionally, XPS analysis indicates that the remaining ligand fragments on the surface of the formed particles act as capping ligands to prevent the particle agglomeration (a inset; Fig. S3†).

chalcogenoureas have been shown as economically viable ligands for metal chalcogenide nanomaterials where their reactivity could easily be tailored via substitution on the nitrogen atoms. ${ }^{40,62}$ As compared to the chalcogenoethers $R_{2} E$, which almost always behave as neutral chalcogen donor ligands, the chemistry of the chalcogenourea ligand is more versatile because of its ability to display following -one/-ate resonance forms (Scheme 3). For selenourea, the selone tautomeric form (I) has been shown to be the more stable and majority form. Unlike the extensively studied thiourea, the research on selenourea remains underdeveloped. In particular, the precursor chemistry of selenourea is scarce. ${ }^{40}$ Here, we have explored $N, N$-dimethylselenourea $\mathrm{Me}_{2} \mathrm{NC}(\mathrm{Se}) \mathrm{NH}_{2}$ (dmsu), which is a commercially available, relatively less expensive and unsymmetrically substituted ligand to provide a desirable reactivity as a reagent for the economical synthesis of $2 \mathrm{D}$ metal chalcogenides. The reactions of $\mathrm{SnCl}_{2}$ with 1 equivalent of $\mathrm{N}, \mathrm{N}$-dimethyl selenourea ( $\mathrm{dmsu}$ ) in dichloromethane at room temperature produced a colorless precipitate of the composition $\left[\mathrm{SnCl}_{2}(\mathrm{dmsu})\right](5)$, as established by the elemental analysis of the powder washed twice with hexane (see the Experimental section). In a similar fashion, the reaction of 
<smiles>[R12]NC(=[W])N[Y10]</smiles>

(I)

(II)

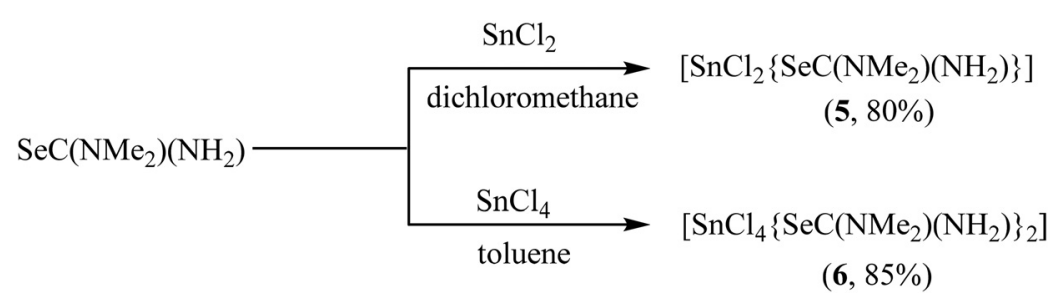

Scheme 3 Two resonance forms, -one (I) and -ate (II) of substituted chalcogenoureas (E = S, Se, Te) (above), and synthesis of complexes of $N, N$-dimethylselenourea with Sn(II) and Sn(IV) 5 and 6 (below).

$\mathrm{SnCl}_{4}$ with 2 equivalents of $d m s u$ in toluene at room temperature proceeded with a change in the solution's color from colorless to yellow and after one hour of stirring, a yellow precipitate was isolated, which was washed twice with hexane and characterized as $\left[\mathrm{SnCl}_{4}(\mathrm{dmsu})_{2}\right](\mathbf{6})$ by elemental analysis. The FT-IR spectra of 5 and $\mathbf{6}$ (Fig. S4†) compare well with the literature data on selenourea complexes, ${ }^{63}$ which confirm the coordination of the $d m s u$ ligand to the tin center through the selenium atom. Unfortunately, the poor solubility of these complexes in common organic solvents hampered our efforts to grow single crystals for X-ray structure determination as well as prevented in-depth spectroscopy characterization in the solution phase.

The suitability of $\mathbf{5}$ and $\mathbf{6}$ as precursors to tin selenide materials was determined by thermogravimetric studies performed under an argon atmosphere. Their TG-DTG curves show a multi- or bi-step decomposition behavior lasting up to $350{ }^{\circ} \mathrm{C}$ and forming $\mathrm{SnSe}$ or $\mathrm{SnSe}_{2}$ as the major end products. The Sn(II) precursor 5 decomposes in several steps, as evident from the four endothermic peaks at 120, 170, 232 and $321{ }^{\circ} \mathrm{C}$ in its DTG curve (Fig. 8a). A residual mass of $\sim 43 \%$ at $350{ }^{\circ} \mathrm{C}$ is much lower than the expected weight of $\mathrm{SnSe}$ as the end product (calculated value $\sim 58 \%$ ), indicating that a part of the material is volatalized during the TGA experiment. On the other hand, the Sn(Iv) precursor 6 exhibits two distinct steps during decomposition (Fig. 8b), as indicated by the two endothermic peaks at 211 and $339{ }^{\circ} \mathrm{C}$ in its DTG curve. The remaining weight of the residue $(\sim 52 \%)$ at $400{ }^{\circ} \mathrm{C}$ indicates the formation of $\mathrm{SnSe}_{2}$ as the end product (calculated value $51 \%$ ). Following these TGA studies, a decomposition temperature of $350{ }^{\circ} \mathrm{C}$ and oleylamine (b.p. $364^{\circ} \mathrm{C}$ ) and/or oleic acid (b.p. $360^{\circ} \mathrm{C}$ ) as solvents were chosen for the decomposition of 5 and 6 via the hot-injection method to obtain tin selenide nanoparticles. Besides their high boiling points, the selection of oleylamine and oleic acid as solvents were based on the fact that the affinity of the $-\mathrm{NH}_{2} /-\mathrm{COOH}$ groups towards the metal center would not only help them to act as coordinating ligands but also the long chain would prevent the growth and agglomeration of the nanostructures due to steric hindrance. ${ }^{64,65}$

The powder XRD pattern of the black precipitate, obtained after the decomposition of tin(II) complex 5 in a $1: 1$ mixture of oleic acid (OA) and oleylamine (OLA) and followed by the usual work-up, shows all the peaks indexing well with the file PDF\# 01-081-9463 of the SnSe phase (Fig. 9a). No other phase was observed. Achieving phase-pure SnSe selectively is significantly important here because previously using similar reagents i.e. $\mathrm{SnCl}_{2} \cdot \mathrm{H}_{2} \mathrm{O}$ and the $d m s u$ ligand in the spray pyrolysis technique, formation of mixed $\mathrm{SnSe} / \mathrm{SnSe}_{2}$ was observed. ${ }^{66}$ In fact, tin selenide materials are quite sensitive to the reaction conditions and phase problems have often been observed. For
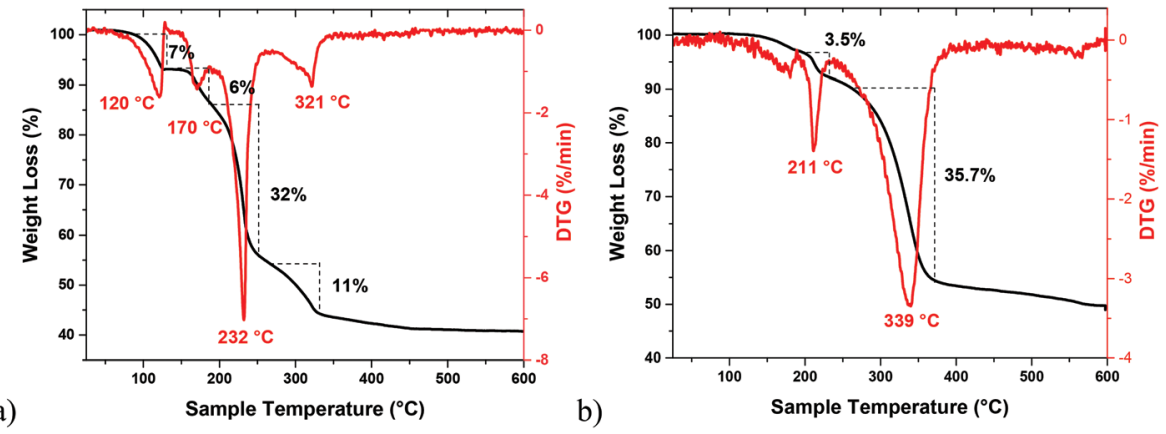

Fig. 8 TG-DTG curves of $\left[\mathrm{SnCl}_{2}(\mathrm{dmsu})\right] 5$ (a) and $\left[\mathrm{SnCl}_{4}(\mathrm{dmsu})_{2}\right] 6$ (b). 


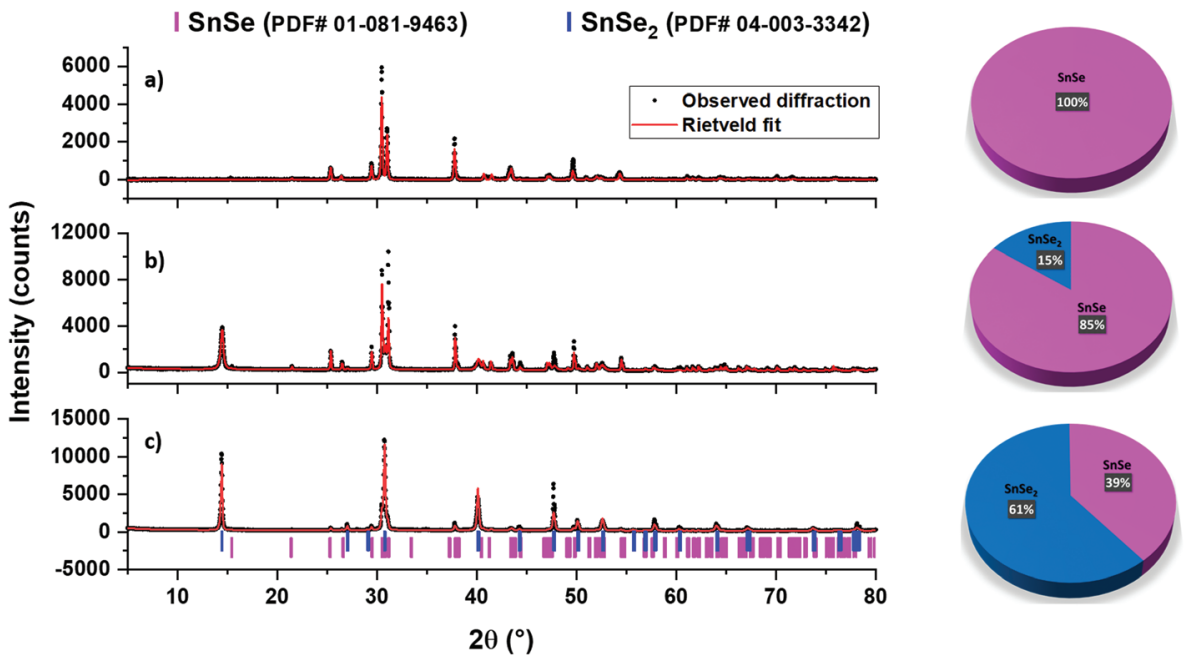

Fig. 9 Rietveld-refined powder XRD patterns of the tin selenide NPs obtained under different conditions. Pure SnSe NPs obtained from the

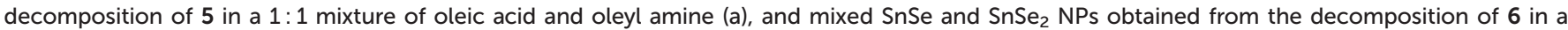
$1: 1$ mixture of oleic acid and oleyl amine (b), or in oleic acid alone (c).

example, $\mathrm{SnSe}_{2}$ materials have been exclusively obtained even when using Sn(II) precursors. ${ }^{67}$

On the other hand, the decomposition of the $\mathrm{Sn}(\mathrm{Iv})$ complex 6 under similar conditions (i.e., in oleic acid and oleylamine at $350^{\circ} \mathrm{C}$ ) led to the formation of a black precipitate, the powder XRD pattern of which indicated the presence of a mixture of two phases i.e., SnSe (PDF\# 01-081-9463) and $\mathrm{SnSe}_{2}$ (PDF\# 04-003-3342) (Fig. 9b). The Rietveld refinement of this XRD pattern indicated the presence of $85 \%$ and $15 \%$ for the $\mathrm{SnSe}$ and $\mathrm{SnSe}_{2}$ phases, respectively. As observed for pure SnSe NPs obtained from 5, the EDX results of the mixed-phase SnSe $+\mathrm{SnSe}_{2} \mathrm{NPs}$ also show the presence of $\mathrm{Sn}, \mathrm{Se}, \mathrm{C}$ and $\mathrm{N}$ elements, therefore indicating the presence of oleylamine as a capping ligand around tin selenide particles. This observation is further confirmed by FT-IR spectra and TGA studies (Fig. 10 and S5 $\dagger$ ). The formation of a mix of Sn(II) and Sn(IV) selenides can be attributed to the reducing ability of the oleylamine. ${ }^{68}$ When 6 was decomposed in oleic acid only, it still produced a mixture of SnSe (PDF\# 01-081-9463) and $\mathrm{SnSe}_{2}$ (PDF\# 04-003-
3342) phases, although the ratio of the $\mathrm{SnSe}_{2}$ phase increased to $61 \%$ (Fig. 9c). These results show that even though getting phase selective tin selenide is a delicate act, a thoughtful selection of an appropriate precursor and careful control of the reaction conditions can help in achieving target materials in a reproducible manner. The presence of significant but varying amounts of the capping ligands (oleylamine or oleic acid) around these NPs is confirmed by their TGA-DTG curves, which show a weight loss of $12-35 \%$ in the temperature range $370-570{ }^{\circ} \mathrm{C}$ (Fig. 10). The higher weight loss in the cases of mixed-phase NPs can partially be attributed to the loss of Se in $\mathrm{SnSe}_{2}$ to convert into the SnSe phase. This is confirmed by the powder XRD studies on the residue left at the end of TGA of the SnSe $(39 \%)+\mathrm{SnSe}_{2}(61 \%)$ sample, which shows the presence of $81 \%$ SnSe and $19 \% \mathrm{SnSe}_{2}$ (Fig. S5 $\dagger$ ).

The presence of capping ligands around NPs prevents their agglomeration, as manifested by the TEM images (Fig. 11a). These images displayed the presence of smooth edged hexagonal and rectangular (or irregular) nanoflakes for the sample
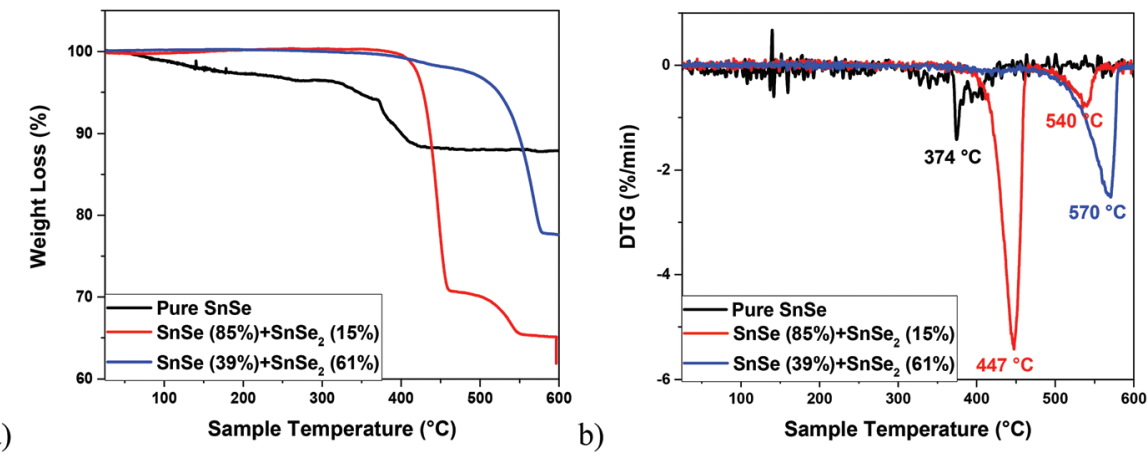

Fig. 10 TGA (a) and DTG (b) curves of the pure SnSe and mixed SnSe and $\mathrm{SnSe}_{2} \mathrm{NPs}$. 

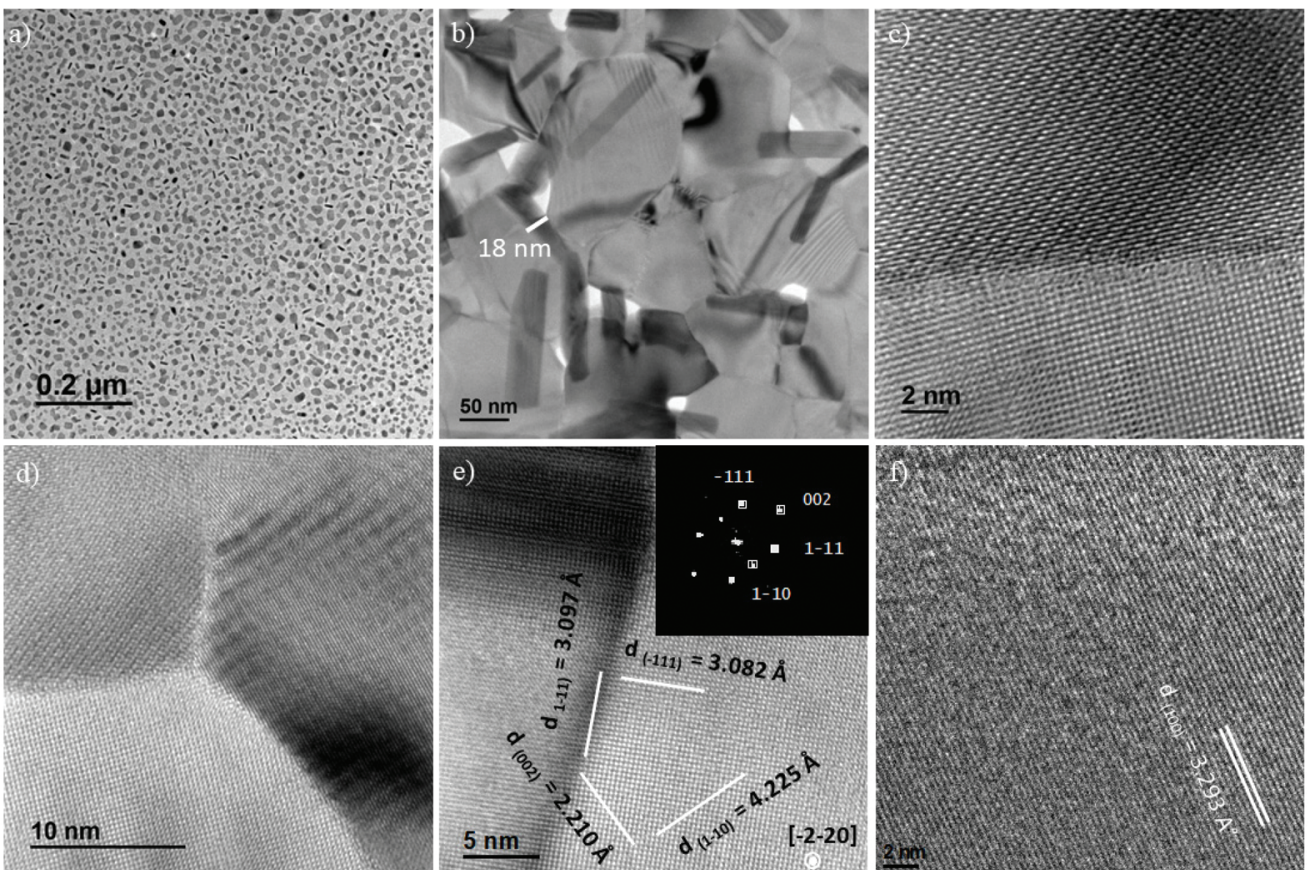

Fig. 11 TEM images (a, b) of nanoflakes obtained by the decomposition of 6 in an OA: OLA (1:1 v/v) solvent mixture. The high resolution TEM images (c-e) and associated FFT (shown as inset) are consistent with orthorhombic SnSe (PDF\# 04-89-0253). HR-TEM image (f) of a representative particle, obtained from the decomposition of 6 in OA, corresponds to the (100) crystal plane of $\mathrm{SnSe}_{2}$ (PDF\# 04-89-2939).

obtained from the decomposition of 6 in an OA: OLA $(1: 1 \mathrm{v} / \mathrm{v})$ solvent mixture. The thickness of nanoflakes obtained was about $18 \mathrm{~nm}$ (Fig. 11b). The high resolution TEM images show clear lattice fringes, thereby confirming the well-crystalline nature of these nanoflakes (Fig. 11c and d). The FFT analysis of some selected particles revealed them to be the ortho-
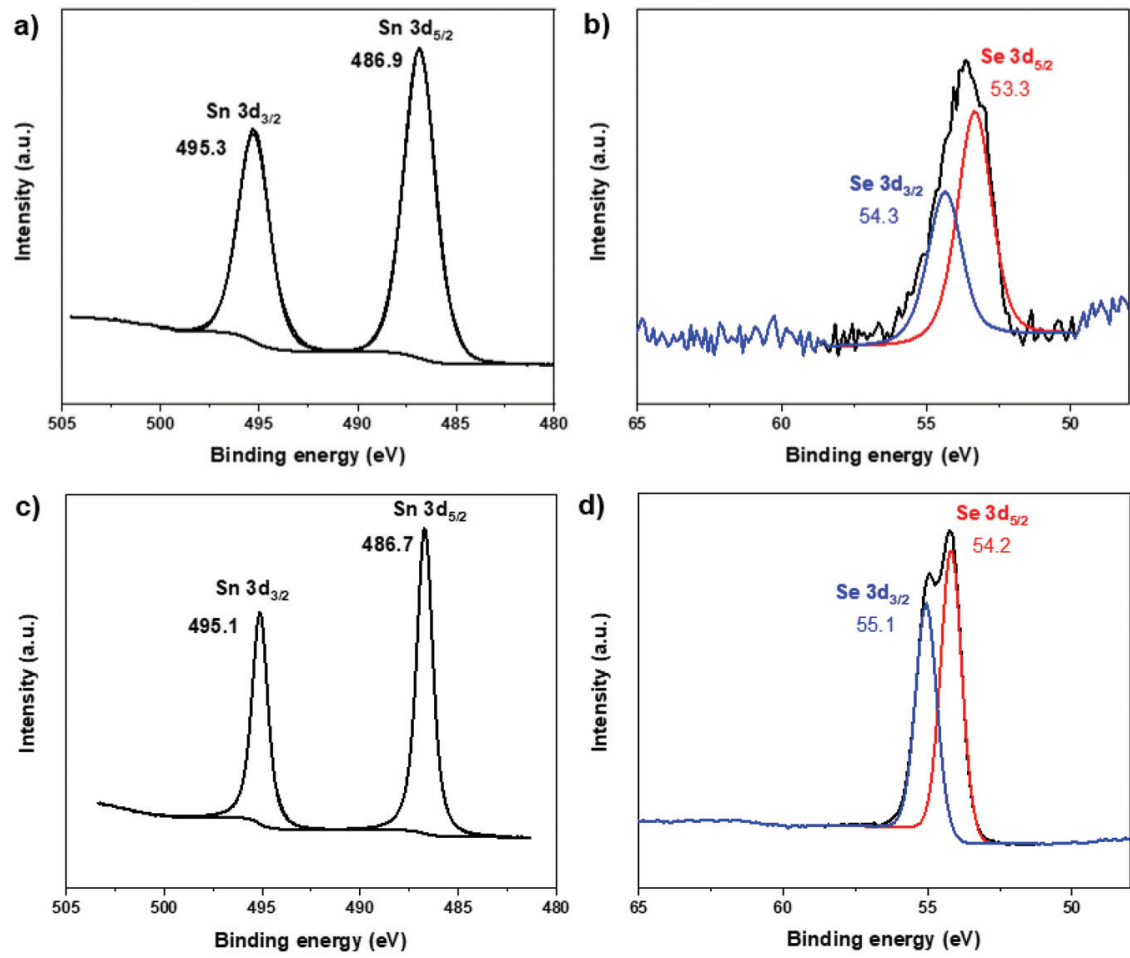

Fig. 12 XPS spectra of single phase ( $100 \% \mathrm{SnSe}$ ) (a and b) and mixed-phase (39\% SnSe $+61 \% \mathrm{SnSe}_{2}$ ) (c and d) tin selenide NPs showing binding energies of Sn 3d and Se 3d. 
rhombic SnSe, which is consistent with the XRD results, showing that this phase is in the vast majority (85\%). For instance, the interplanar distances of 2.210, 3.082, 3.097 and $4.225 \AA$ for the particles shown in Fig. 11e, and the associated FFT analysis (inset), were consistent with the (002), (1-11) and (1-10) crystal planes of the orthogonal SnSe (PDF\# 04-89-0253) (Fig. 11e). The morphology of the nanoflakes obtained from the decomposition of 6 in OA alone was quite similar to those obtained in the OA: OLA solvent mixture. However, in agreement with the XRD results, the majority of the particles was of the $\mathrm{SnSe}_{2}$ phase. The HR-TEM image of a representative particle shows an interplanar distance of $3.293 \AA$ (Fig. 11f), which is consistent with the (100) crystal plane of $\mathrm{SnSe}_{2}$ (PDF\# 04-89$2939 ; d_{(100)}$ theor. value $=3.300 \AA$ ) .

Two representative samples, i.e. single phase (100\% SnSe) and mixed-phase $\left(39 \% \mathrm{SnSe}+61 \% \mathrm{SnSe}_{2}\right)$ tin selenide NPs, were further studied by XPS spectroscopy. The survey spectra reveal that in addition to tin and selenium, these NPs also contain a high carbon content due to the presence of capping ligands. In the core level XPS spectra of these two samples (Fig. 12), the $3 \mathrm{~d}_{5 / 2}$ and $3 \mathrm{~d}_{3 / 2}$ peaks for $\mathrm{Sn}$ appear at binding energies of $486.8 \pm 0.1$ and $495.2 \pm 0.1 \mathrm{eV}$, respectively, whereas the corresponding peaks for Se appear at 53.3-54.2 and 54.3-55.1 eV. While the chemical state differentiation between $\mathrm{Sn}$ (II) and $\mathrm{Sn}$ (IV) is difficult due to overlapping Sn 3d values for these two oxidation states, ${ }^{69}$ the Se $3 \mathrm{~d}$ binding energies unequivocally correspond to $\mathrm{Se}^{2-31} \mathrm{No}$ obvious peaks for elemental tin or selenium were observed indicating good purity of the as-synthesized NPs.

\section{Conclusion}

Phase selective synthesis of tin chalcogenides, which exhibit a variety of phases ( $\mathrm{SnE}, \mathrm{Sn}_{2} \mathrm{E}_{3}$, and $\mathrm{SnE}_{2} ; \mathrm{E}=\mathrm{S}, \mathrm{Se}$ ) is a delicate task. We exploit here the versatile coordination behavior and facile chalcogenide atom transfer ability of the ligands $\mathrm{N}$-alkyl diethanethiolamine and $N, N$-dimethyl selenourea to obtain new $\mathrm{Sn}$ (II) and $\mathrm{Sn}$ (Iv) molecular precursors containing direct $\mathrm{Sn}-\mathrm{E}$ bonds (E = S or Se). These undergo facile decomposition under different conditions (solid/solution phase, thermal/ microwave heating, single/mixed solvents, varying temperature, etc.) to afford phase-pure or mixed-phase tin chalcogenide nanostructures with defined ratios. These results show that a thoughtful selection of appropriate precursors and careful control of the reaction conditions can help in achieving target materials in a reproducible manner.

Having established molecular routes to tin sulfide and selenide nanoparticles, we are currently working to combine these routes to obtain mixed-anion compounds $\mathrm{SnS}_{x} \mathrm{Se}_{y}$ (where $x+y$ $=1$ ) and SnSSe, which are expected to have novel and exciting properties due to the introduced asymmetry in their structures. Indeed, Guo et al. predicted very recently by means of first-principles calculations high carrier mobility and large absorption coefficients in the visible light region in Janus-like SnSSe materials, which show greater potential for electronic and thermoelectric applications. ${ }^{70}$

\section{Experimental section}

All the experiments were performed under an argon or nitrogen atmosphere using standard Schlenk, Stock-type and glovebox techniques. Tin(II) and tin(Iv) chloride and 1,1-dimethyl-2selenourea were procured from Aldrich and used without further purification. Toluene, $n$-heptane, dichloromethane and tetrahydrofuran (THF) used for the synthesis of metal complexes were dried using MB SPS-800 or standard methods with appropriate desiccating reagents and distilled prior to their use. $^{71}$

Powder X-ray diffraction (XRD) patterns were measured using a Bruker D8 Advance A25 system with $\mathrm{Cu} \mathrm{K} \alpha 1+2(\lambda=$ $0.154184 \mathrm{~nm}$ ) radiation at $50 \mathrm{kV}$ and $35 \mathrm{~mA}$ or a STOE-STADI MP diffractometer operating in reflection mode using Mo K $\alpha$ $(\lambda=0.71073 \AA)$ radiation. Measured peak patterns were compared to reference powder diffraction files (PDFs). The infrared spectra were recorded either as Nujol mulls on a Bruker Vector 22 FT-IR spectrometer or as dry powders/oils on a PerkinElmer FT-IR spectrometer at room temperature and registered from 4000 to $400 \mathrm{~cm}^{-1}$. NMR spectra were recorded on a Bruker Avance II 300 or Bruker AC-300 spectrometer; chemical shifts are quoted in parts per million relative to external TMS $\left({ }^{1} \mathrm{H}\right.$, ${ }^{13} \mathrm{C}$ and ${ }^{119} \mathrm{Sn}$ ) recorded in $\mathrm{CDCl}_{3}$ and $\mathrm{C}_{6} \mathrm{D}_{6}$. TEM experiments were performed using a JEM-2100F system with $200 \mathrm{kV}$ field emission (FE), a JEOL 2010 LaB6 system and a JEOL JEM-2200FS with $200 \mathrm{kV}$ FE. The tin, sulfur, and selenium contents were determined by inductively coupled plasma optical emission spectroscopy (ICP-OES). Thermogravimetric analyses (TGA) were performed with a TGA/differential scanning calorimetry 1 STARe system from Mettler Toledo under a nitrogen atmosphere $\left(25 \mathrm{~mL} \mathrm{~min}^{-1}\right)$ at a rate of $5-10{ }^{\circ} \mathrm{C} \mathrm{min}^{-1}$ from 30 to $800^{\circ} \mathrm{C}$. Therefore, around $8 \mathrm{mg}$ of the sample was sealed in a $100 \mu \mathrm{L}$ aluminum crucible in a glovebox or under ambient conditions. Mass spectra were recorded on a Thermo Quest Finnigan MAT 95 (EI, Electron ionization) and conducted with an electron energy of $20 \mathrm{eV}$ or $70 \mathrm{eV}$ at $10^{-6} \operatorname{mbar}$. CHN(S) combustion analysis (elemental analysis) were determined with a device by the company HEKAtech of the type CHNS EuroEA 3000 Analyzer or Vario Micro Cube from the company Elementar. An electron spectrometer (Kratos Axis Ultra DLD) with an $\mathrm{Al} \mathrm{K} \alpha(1486.6 \mathrm{eV})$ radiation source was used to perform the X-ray photoelectron spectroscopy (XPS) analysis of the samples. Corrections on the constant charging of the XPS spectra were made by $\mathrm{C} 1 \mathrm{~s}$ of adventitious carbon (binding energy of $284.6 \mathrm{eV}$ ). Data collection for single-crystal X-ray structure elucidation was performed on a STOE IPDS 2T/D8 diffractometer using graphite-monochromated Mo $\mathrm{K} \alpha$ radiation $(0.71073 \AA)$. The data were corrected for Lorentz and polarization effects. A numerical absorption correction based on crystal-shape optimization was applied for all data. The programs used in this work are STOE's X-Area, including X-RED ${ }^{72}$ and $\mathrm{X}$-Shape ${ }^{73}$ for data reduction and absorption correction, SIR-92 and SHELXL-2014 for structure solution, ${ }^{74,75}$ and SHELXL $^{74}$ for structure refinement. CCDC 2104958-2104960† contain the supplementary crystallographic data for this 
article. Microwave assisted thermal decomposition experiments have been performed with a Discover microwave system from CEM using a fixed power program. The size and morphology of the deposited nanostructures were analyzed using a Nova Nano SEM 430 system, a field-emission scanning electron microscope (SEM).

Complexes 1-6 were synthesized under a nitrogen/argon atmosphere using Schlenk line techniques. Working under reduced pressure means always $1 \times 10^{-3}$ mbar. The ligands $\quad \mathrm{N}$-methyldiethanthiolamine $\left(\text { mdetaH }_{2}\right)^{38}$ and $N$-ethyldiethanthiolamine $\left(\operatorname{edetaH}_{2}\right)^{76}$ have been synthesized according to the optimized synthesis routes described elsewhere.

\subsection{Synthesis of $\left[\mathrm{Sn}\left\{\left(\mathrm{SC}_{2} \mathrm{H}_{4}\right)_{2} \mathrm{NMe}\right\}\right](1)$}

To a solution of $\left[\mathrm{Sn}\left(\mathrm{N}\left(\mathrm{SiMe}_{3}\right)_{2}\right)_{2}\right](0.34 \mathrm{~g}, 0.64 \mathrm{mmol})$ in $10 \mathrm{~mL}$ of toluene $0.10 \mathrm{~g}$ of $(0.64 \mathrm{mmol}) \mathrm{N}$-methyldiethanthiolamine were added. Upon addition of the ligand to the orange solution a color change was observed immediately, and a slightly yellow precipitate was formed. The reaction mixture was stirred for $30 \mathrm{~min}$ at room temperature. Afterwards, the solvent was removed under reduced pressure and the slightly yellow solid was washed several times with $n$-heptane. After drying under reduced pressure, the product was isolated as a pale yellow solid in a yield of $94 \%(0.16 \mathrm{~g}, 0.60 \mathrm{mmol})$. Calc. for 1 (M. wt 269.0): C, 22.4, H, 4.1, N, 5.2. Found: C, 23.3, H, 4.4, N, 5.2.

${ }^{1} \mathrm{H}-\mathrm{NMR}$ (DMSOd-6, $\left.300 \mathrm{MHz}, \mathrm{RT}, \mathrm{ppm}\right): 2.48(\mathrm{~s}, 3 \mathrm{H}$, $\left.-\mathrm{NCH}_{3}\right), 2.60-2.82\left(\mathrm{~m}, 4 \mathrm{H},-\mathrm{SCH}_{2} \mathrm{CH}_{2} \mathrm{~N}-\right), 2.83-2.95(\mathrm{~m}, 4 \mathrm{H}$, $-\mathrm{SCH}_{2} \mathrm{CH}_{2} \mathrm{~N}-$ ).

${ }^{13} \mathrm{C}-\mathrm{NMR}$ (DMSO d-6, $\left.75 \mathrm{MHz}, \quad \mathrm{RT}, \quad \mathrm{ppm}\right): \quad 62.3$ $\left(-\mathrm{NCH}_{2} \mathrm{CH}_{2} \mathrm{~S}-\right), 42.7\left(-\mathrm{NCH}_{3}\right), 26.8\left(-\mathrm{SCH}_{2}-\mathrm{CH}_{2} \mathrm{~N}-\right)$.

${ }^{119}$ Sn-NMR (DMSO d-6, 111.9 MHz, RT, ppm): 123.8.

EI-MS $\left(70 \mathrm{eV}, 170{ }^{\circ} \mathrm{C}\right): \mathrm{m} / \mathrm{z}(\%$, fragment $)=269(78$, $\left.\left[\mathrm{SnS}_{2} \mathrm{C}_{5} \mathrm{H}_{11} \mathrm{~N}\right]^{+}\right), 267\left(58,\left[\mathrm{SnS}_{2} \mathrm{C}_{5} \mathrm{H}_{11} \mathrm{~N}\right]^{+}\right), 209\left(12,\left[\mathrm{SnSC}_{3} \mathrm{H}_{7} \mathrm{~N}\right]^{+}\right)$, $117\left(52,\left[\mathrm{SC}_{5} \mathrm{H}_{11} \mathrm{~N}\right]^{+}\right), 116\left(24,\left[\mathrm{SC}_{5} \mathrm{H}_{10} \mathrm{~N}\right]^{+}\right), 91\left(40,\left[\mathrm{SC}_{3} \mathrm{H}_{9} \mathrm{~N}\right]^{+}\right)$, $71\left(64,\left[\mathrm{C}_{4} \mathrm{H}_{9} \mathrm{~N}\right]^{+}\right), 58\left(13,\left[\mathrm{C}_{3} \mathrm{H}_{8} \mathrm{~N}\right]^{+}\right), 43\left(44,\left[\mathrm{C}_{2} \mathrm{H}_{5} \mathrm{~N}\right]^{+}\right)$.

\subsection{Synthesis of $\left[\mathrm{Sn}\left\{\left(\mathrm{SC}_{2} \mathrm{H}_{4}\right)_{2} \mathrm{NEt}\right\}\right]$ (2)}

$0.56 \mathrm{~g}(1.27 \mathrm{mmol})$ of $\left[\mathrm{Sn}\left(\mathrm{N}\left(\mathrm{SiMe}_{3}\right)_{2}\right)_{2}\right]$ was dissolved in $25 \mathrm{~mL}$ of dry toluene and $0.24 \mathrm{~g}(1.46 \mathrm{mmol})$ of $N$-ethyldiethanthiolamine was added slowly to it under constant stirring. The orange solution turned directly pale yellow by adding the ligand and a colourless solid was formed. The reaction mixture was stirred for $30 \mathrm{~min}$ and the solvent was removed under reduced pressure. The colorless precipitate was washed several times with $n$-heptane and the product was isolated as a slightly yellow solid in a yield of $80 \%(0.29 \mathrm{~g}$, $1.02 \mathrm{mmol}$ ). Calc. for 4 (M. wt 283.0): C, 25.6, H, 4.7, N, 5.0, S, 22.7. Found: C, 26.4, H, 5.0, N, 4.7, S, 23.9. FT-IR $\left(\mathrm{cm}^{-1}\right)$ : 2911w, 2835s.

${ }^{1} \mathrm{H}-\mathrm{NMR}$ ( $\left.\mathrm{CDCl}_{3}, 300 \mathrm{MHz}, \mathrm{RT}, \mathrm{ppm}\right):(300 \mathrm{MHz}, \mathrm{DMSO}-\mathrm{d} 6)$ : $\delta[\mathrm{ppm}]=2.91\left(\mathrm{~m}, 2 \mathrm{H},-\mathrm{N}-\mathrm{CH}_{2} \mathrm{CH}_{3}\right), 2.82\left(\mathrm{~m}, 4 \mathrm{H},-\mathrm{S}-\mathrm{CH}_{2}-\mathrm{CH}_{2}-\right.$ $\mathrm{NR}_{2}$ ), 2.68 (m, 4H, $\left.-\mathrm{S}-\mathrm{CH}_{2}-\mathrm{CH}_{2}-\mathrm{NR}_{2}\right), 1.00\left(\mathrm{t}, 3 \mathrm{H}, \mathrm{N}-\mathrm{CH}_{2} \mathrm{CH}_{3}\right)$.

${ }^{13} \mathrm{C}-\mathrm{NMR}\left(\mathrm{CDCl}_{3}, 75 \mathrm{MHz}, \mathrm{RT}, \mathrm{ppm}\right):(75 \mathrm{MHz}, \mathrm{DMSO}-\mathrm{d} 6): \delta$ $[\mathrm{ppm}]=51.2\left(-\mathrm{S}-\mathrm{CH}_{2}-\mathrm{CH}_{2}-\mathrm{NR}_{2}\right), 47.1\left(-\mathrm{N}-\mathrm{CH}_{2} \mathrm{CH}_{3}\right), 25.3(-\mathrm{S}-$ $\left.\mathrm{CH}_{2}-\mathrm{CH}_{2}-\mathrm{NR}_{2}\right), 8.3\left(\mathrm{~N}-\mathrm{CH}_{2} \mathrm{CH}_{3}\right)$.
EI-MS: (70 eV, $\left.184{ }^{\circ} \mathrm{C}\right): \mathrm{m} / z(\%$, fragment $)=283(31$, $\left.\left[\mathrm{SnS}_{2} \mathrm{C}_{6} \mathrm{H}_{13} \mathrm{~N}\right]^{+}\right), 281\left(25,\left[\mathrm{SnS}_{2} \mathrm{C}_{6} \mathrm{H}_{13} \mathrm{~N}\right]^{+}\right), 223\left(8,\left[\mathrm{SnSC}_{4} \mathrm{H}_{9} \mathrm{~N}\right]^{+}\right)$, $\left.163\left(69,\left[\mathrm{SnC}_{2} \mathrm{H}_{5} \mathrm{~N}\right]^{+}\right), 130\left(65, \mathrm{SC}_{6} \mathrm{H}_{12} \mathrm{~N}\right]^{+}\right), 116\left(54,\left[\mathrm{SC}_{5} \mathrm{H}_{9} \mathrm{~N}\right]^{+}\right)$, $102\left(100,\left[\mathrm{SC}_{4} \mathrm{H}_{8} \mathrm{~N}\right]^{+}\right), 84\left(21,\left[\mathrm{C}_{5} \mathrm{H}_{10} \mathrm{~N}\right]^{+}\right), 71\left(41,\left[\mathrm{C}_{4} \mathrm{H}_{9} \mathrm{~N}\right]^{+}\right), 56$ $\left(35,\left[\mathrm{C}_{3} \mathrm{H}_{6} \mathrm{~N}\right]^{+}\right), 42\left(37,\left[\mathrm{C}_{2} \mathrm{H}_{8}\right]^{+}\right), 28\left(26,\left[\mathrm{C}_{2} \mathrm{H}_{4}\right]^{+}\right), 18\left(77,\left[\mathrm{H}_{2} \mathrm{O}\right]^{+}\right)$.

\subsection{Synthesis of $\left[\operatorname{Sn}\left\{\left(\mathrm{SC}_{2} \mathrm{H}_{4}\right)_{2} \mathrm{NMe}\right\}_{2}\right](3)$}

To a solution of $\left[\mathrm{Sn}\left(\mathrm{O}^{t} \mathrm{Bu}\right)_{4}\right](0.13 \mathrm{~g}, 0.30 \mathrm{mmol})$ in $10 \mathrm{~mL}$ of toluene $0.09 \mathrm{~g}(0.6 \mathrm{mmol})$ of $N$-methyldiethanthiolamine were added, while a colorless precipitate was immediately formed. The reaction mixture was stirred for $30 \mathrm{~min}$ at room temperature before the solvent was removed under reduced pressure. The colorless crystalline product was washed several times with $n$-heptane and dried under reduced pressure. The crystalline product was isolated in a yield of $87 \%(0.11 \mathrm{~g}$, $0.26 \mathrm{mmol}$ ). Calc. for 3 (M. wt 418.0): C, 28.8, H, 5.3, N, 6.7. Found: C, 29.2, H, 5.2, N, 6.2. FT-IR $\left(\mathrm{cm}^{-1}\right)$ : 2967w, 2836w.

${ }^{1} \mathrm{H}-\mathrm{NMR}\left(\mathrm{CDCl}_{3}, 300 \mathrm{MHz}, \mathrm{RT}, \mathrm{ppm}\right): 2.43$ (s, 6H, $-\mathrm{NCH}_{3}$ ), $2.71\left(\mathrm{~m}, 4 \mathrm{H},-\mathrm{NCH}_{2} \mathrm{CH}_{2} \mathrm{~S}-\right)$, 2.87 (m, 4H, $\left.-\mathrm{NCH}_{2} \mathrm{CH}_{2} \mathrm{~S}-\right)$.

${ }^{13} \mathrm{C}-\mathrm{NMR}\left(\mathrm{CDCl}_{3}, 75 \mathrm{MHz}, \mathrm{RT}, \mathrm{ppm}\right): 25.4\left(-\mathrm{SCH}_{2} \mathrm{CH}_{2} \mathrm{~N}-\right)$, $43.9\left(-\mathrm{NCH}_{3}\right), 57.6\left(-\mathrm{SCH}_{2} \mathrm{CH}_{2} \mathrm{~N}\right)$.

${ }^{119} \mathrm{Sn}-\mathrm{NMR}\left(\mathrm{CDCl}_{3}, 111.9 \mathrm{MHz}, \mathrm{RT}, \mathrm{ppm}\right):-182.5$.

\subsection{Synthesis of $\left[\mathrm{Sn}\left\{\left(\mathrm{SC}_{2} \mathrm{H}_{4}\right)_{2} \mathrm{NEt}\right\}_{2}\right](4)$}

$0.51 \mathrm{~g}(1.2 \mathrm{mmol})$ of tin tert-butoxide and $10 \mathrm{ml}$ of toluene were filled in a round flask. $0.40 \mathrm{~g}(2.4 \mathrm{mmol})$ of $N$-ethyl-diethanolthioamine were added under stirring and the solution turned directly colourless. The mixture was stirred for $15 \mathrm{~min}$. The solvent was removed under reduced pressure and the colourless product was isolated with a yield of $87 \%(0.45 \mathrm{~g}$, $1.0 \mathrm{mmol}$ calc. for 2 (M. wt 446.0): C, 32.4, H, 5.9, N, 6.3. Found: C, 32.5, H, 5.8, N, 6.0. FT-IR ( $\left.\mathrm{cm}^{-1}\right)$ : 2979-2886s, 2846w.

${ }^{1} \mathrm{H}-\mathrm{NMR}\left(\mathrm{CDCl}_{3}, 300 \mathrm{MHz}, \mathrm{RT}, \mathrm{ppm}\right): 3.10-2.86(\mathrm{~m}, 12 \mathrm{H}$, $\left.\mathrm{CH}_{3}-\mathrm{CH}_{2}-\mathrm{N}-\left(\mathrm{CH}_{2}-\mathrm{CH}_{2}-\mathrm{S}-\right)_{2}\right), 2.75-2.72\left(\mathrm{~m}, 8 \mathrm{H},-\mathrm{N}-\left(\mathrm{CH}_{2}-\right.\right.$ $\left.\left.\mathrm{CH}_{2}-\mathrm{S}-\right)_{2}\right), 1.06$ (t, 6H, $\mathrm{CH}_{3}-\mathrm{CH}_{2}-\mathrm{N}-$ ).

${ }^{13} \mathrm{C}-\mathrm{NMR}\left(\mathrm{CDCl}_{3}, 75 \mathrm{MHz}, \mathrm{RT}, \mathrm{ppm}\right): 53.69\left(-\mathrm{N}-\mathrm{CH}_{2}-\mathrm{CH}_{2}-\right.$ $\mathrm{S}-)$, $48.74\left(\mathrm{CH}_{3}-\mathrm{CH}_{2}-\mathrm{N}-\right), 26.26\left(-\mathrm{N}-\mathrm{CH}_{2}-\mathrm{CH}_{2}-\mathrm{S}-\right), 8.42\left(\mathrm{CH}_{3}-\right.$ $\left.\mathrm{CH}_{2}-\mathrm{N}-\right)$.

\subsection{Synthesis of $\left[\mathrm{SnCl}_{2}(\mathrm{dmsu})\right](5)$}

The addition of dmsu $(0.14 \mathrm{~g}, 0.96 \mathrm{mmol})$ to $\mathrm{SnCl}_{2} \cdot \mathrm{H}_{2} \mathrm{O}$ $(0.22 \mathrm{~g}, 0.96 \mathrm{mmol})$ solution in $\mathrm{CH}_{2} \mathrm{Cl}_{2}$ led to the formation of an off-white colored precipitate. The solution was stirred for two hours under an $\mathrm{Ar}$ atmosphere at room temperature to ensure the completion of the reaction. The off-white powder obtained was washed twice with hexane. Yield, $0.2 \mathrm{~g}$ (80\%). Calc. for 5 (M. wt 339.7): C, 10.59, H, 2.35, N, 8.24, Sn, 35.03; Se, 23.25. Found: C, 10.53, H, 2.39, N, 8.20, Sn, 34.35\%; Se, 23.11\%. FT-IR (Nujol, $\mathrm{cm}^{-1}$ ): $3428 \mathrm{~m}, 3380 \mathrm{w}, 3168 \mathrm{w}, 2925 \mathrm{~s}$, 2723w, 1714s, 1640 m, 1456 m, 1376 m, 1157w, 1040w, 722 m.

${ }^{1} \mathrm{H}-\mathrm{NMR}\left(\mathrm{CDCl}_{3}, 300 \mathrm{MHz}, \mathrm{RT}, \mathrm{ppm}\right): 3.37$ (s, 6H, Me), 6.20 (s, $2 \mathrm{H}, \mathrm{NCH}_{2}$ ).

\subsection{Synthesis of $\left[\mathrm{SnCl}_{4}(\mathrm{dmsu})_{2}\right](6)$}

The addition of dmsu $(0.36 \mathrm{~g}, 2.35 \mathrm{mmol})$ to $\mathrm{SnCl}_{4}(0.30 \mathrm{~g}$, $1.17 \mathrm{mmol}$ ) solution in toluene led to an instant precipitation 
and change in the color, first to green and then to milky yellow. The solution was stirred for two hours under an $\mathrm{Ar}$ atmosphere at room temperature and the yellow powder was separated by filtration. Yield, $0.56 \mathrm{~g}$ (85\%). Calc. for 6 (M. wt 560.7): C, 12.84, H, 2.85, N, 9.99, Sn, 21.22\%; Se, $31.74 \%$. Found: C, 10.79, H, 2.80, N, 9.87, Sn, 21.10\%; Se, 31.07\%. FT-IR (Nujol, cm ${ }^{-1}$ ): 2927s, $1715 \mathrm{~m}, 1623 \mathrm{~m}, 1464 \mathrm{~s}, 1384 \mathrm{~s}$, 1162w, 1045w, 719w.

${ }^{1} \mathrm{H}-\mathrm{NMR}\left(\mathrm{CDCl}_{3}, 300 \mathrm{MHz}, \mathrm{RT}, \mathrm{ppm}\right): 3.39$ (s, 12H, Me), $6.23\left(\mathrm{~s}, 4 \mathrm{H}, \mathrm{NCH}_{2}\right)$.

\subsection{Decomposition of 5}

Solution (A) consisting of $2 \mathrm{~mL}$ each of oleic acid and oleylamine was taken in a 3-neck flask connected to a condenser, stirred and heated to $350{ }^{\circ} \mathrm{C}$. Separately, another solution (B) was prepared by dissolving $5(0.15 \mathrm{~g}, 1.29 \mathrm{mmol})$ in $2 \mathrm{~mL}$ of each oleic acid and oleylamine, and injected at once into the preheated solution (A). The resulting reaction mixture was refluxed for one hour and the black precipitate obtained was washed 3 times with ethanol and pentane, and dried at room temperature. Yield, 0.12 g. FT-IR (Nujol, $\mathrm{cm}^{-1}$ ): $2920 \mathrm{~m}$, $2847 \mathrm{w}, 2361 \mathrm{~m}, 2337 \mathrm{w}, 928 \mathrm{w}$.

\subsection{Decomposition of 6}

Using the above method, decomposition of $6(0.20 \mathrm{~g}$, $0.35 \mathrm{mmol}$ ) in a $1: 1$ solution of oleic acid and oleyl amine at $350{ }^{\circ} \mathrm{C}$ gave a black precipitate $(0.04 \mathrm{~g})$ which was washed 3 times with ethanol and pentane, and then dried at room temperature. FT-IR (Nujol, $\mathrm{cm}^{-1}$ ): $3308 \mathrm{~m}, 2920 \mathrm{~s}, 2847 \mathrm{~s}, 1641 \mathrm{~s}$, $1556 \mathrm{~m}, 1470 \mathrm{~m}, 959 \mathrm{~m}, 719 \mathrm{w}$.

\section{Author contributions}

The conceptualization, formal analysis and synthetic work, investigation, visualization, and writing have been carried out by V. Brune; A. Sutorius contribute with synthetic work and formal analysis of complex 4; M. Wilhelm performed the XPS analysis for the tin sulfide part; C. Hegemann provided the molecular structures of compounds 1a, 3 and 4; F. Hartl contributed to writing and editing the introduction part concerning the tin sulfides; resources have been provided by the University of Cologne. For review of the writing and editing U. Atatmürk was responsible. S. Mathur accomplished the scientific supervision, editing of the text and project administration. S. Mishra conceived and supervised the work on the tin selenide part, did some patch-up experimental work, and wrote the manuscript. N. Raydan, B. Purohit and S. Gahlot synthesized and characterized the precursors and the NPs. P. Bargirla and L. Burel performed the XPS and TEM measurements, respectively. All authors discussed the results and commented on the final manuscript.

Both $1^{\text {st }}$ authors (V. Brune and N. Rayan) agree to the shared authorship. Both have contributed equally on this manuscript.

\section{Conflicts of interest}

There are no conflicts of interest to declare.

\section{Acknowledgements}

The authors kindly acknowledge the financial support obtained in the framework of a DFG project, "Development of new precursors for chemical vapor deposition” (MA 2359/43-1). The authors thank for the financial and infrastructural support provided by the University of Cologne (UoC) and Université Claude Bernard Lyon 1, CNRS and the AuvergneRhone-Alpes Region (SCUSI 2017009361 01) for partial financial support to N. R. We also thank Y. Aizac (XRD) and P. Mascunan (elemental analyses) of IRCELYON, as well as N. Tosun (TEM), Chr. Schmitz and D. Pullem (elemental analysis) from UoC for providing timely analysis.

\section{References}

1 M. Kumar, S. Rani, Y. Singh, K. S. Gour and V. N. Singh, RSC Adv. , 2021, 11, 6477-6503.

2 M. Guc, J. Andrade-Arvizu, I. Y. Ahmet, F. Oliva, M. Placidi, X. Alcobé, E. Saucedo, A. Pérez-Rodríguez, A. L. Johnson and V. Izquierdo-Roca, Acta Mater., 2020, 183, 1-10.

3 V. R. Minnam Reddy, S. Gedi, B. Pejjai and C. Park, J. Mater. Sci.: Mater. Electron., 2016, 27, 5491-5508.

4 D. J. Lewis, P. Kevin, O. Bakr, C. A. Muryn, M. A. Malik and P. O’Brien, Inorg. Chem. Front., 2014, 1, 577-598.

5 S. S. Hegde, A. G. Kunjomana, K. A. Chandrasekharan, K. Ramesh and M. Prashantha, Phys. B, 2011, 406, 1143-1148.

6 H. Kawamoto, N. Higashitarumizu, N. Nagamura, M. Nakamura, K. Shimamura, N. Ohashi and K. Nagashio, Nanoscale, 2020, 12, 23274-23281.

7 J. M. Gonzalez and I. I. Oleynik, Phys. Rev. B, 2016, 94, 110.

8 J. M. Skelton, L. A. Burton, F. Oba and A. Walsh, J. Phys. Chem. C, 2017, 121, 6446-6454.

9 L. A. Burton, D. Colombara, R. D. Abellon, F. C. Grozema, L. M. Peter, T. J. Savenije, G. Dennler and A. Walsh, Chem. Mater., 2013, 25, 4908-4916.

10 L. A. Burton and A. Walsh, J. Phys. Chem. C, 2012, 116, 24262-24267.

11 J. Kim, J. Kim, S. Yoon, J. Kang, C. Jeon and W. Jo, J. Phys. Chem. C, 2018, 122, 3523-3532.

12 F. Y. Ran, Z. Xiao, Y. Toda, H. Hiramatsu, H. Hosono and T. Kamiya, Sci. Rep., 2015, 5, 10428.

13 G. Duvjir, T. Min, T. Thi Ly, T. Kim, A. T. Duong, S. Cho, S. H. Rhim, J. Lee and J. Kim, Appl. Phys. Lett., 2017, 110, 262106.

14 B. Qin, W. He and L. D. Zhao, J. Materiomics, 2020, 6, 671676.

15 N. E. Makori, I. A. Amatalo, P. M. Karimi and W. K. Njoroge, Am. J. Condens. Matter Phys., 2014, 4, 87-90. 
16 U. Chalapathi, B. Poornaprakash and S. H. Park, Sol. Energy, 2016, 139, 238-248.

17 B. Ul Haq, S. AlFaify, R. Ahmed, F. K. Butt, A. Laref and M. Shkir, Phys. Rev. B, 2018, 97, 1-12.

18 A. Sanchez-Juarez and A. Ortíz, Semicond. Sci. Technol., 2002, 17, 931-937.

19 (a) R. H. Williams, R. B. Murray, D. W. Govan, J. M. Thomas and E. L. Evans, J. Phys. C: Solid State Phys., 1973, 6, 3631; (b) M. Schlüter and M. L. Cohen, Phys. Rev. B: Solid State, 1976, 14, 424-431.

20 S. Pulipaka, A. K. S. Koushik, N. Boni, M. Deepa and P. Meduri, Int. J. Hydrogen Energy, 2019, 44, 1158411592.

21 S. R. Damkale, S. S. Arbuj, G. G. Umarji, R. P. Panmand, S. K. Khore, R. S. Sonawane, S. B. Rane and B. B. Kale, Sustainable Energy Fuels, 2019, 3, 3406-3414.

22 Y. Sun, H. Cheng, S. Gao, Z. Sun, Q. Liu, Q. Leu, F. Lei, T. Yao, J. He, S. Wei and Y. Xie, Angew. Chem., Int. Ed., 2012, 51, 8727-8731.

23 H. S. Song, S. L. Li, L. Gao, Y. Xu, K. Ueno, J. Tang, Y. B. Cheng and K. Tsukagoshi, Nanoscale, 2013, 5, 96669670.

24 T. S. Pan, D. De, J. Manongdo, A. M. Guloy, V. G. Hadjiev, Y. Lin and H. B. Peng, Appl. Phys. Lett., 2013, 103.

25 J. Z. Ou, W. Ge, B. Carey, T. Daeneke, A. Rotbart, W. Shan, Y. Wang, Z. Fu, A. F. Chrimes, W. Wlodarski, S. P. Russo, Y. X. Li and K. Kalantar-zaden, ACS Nano, 2015, 9, 1031310323.

26 Ó. L. C. Moreira, W. Y. Cheng, H. R. Fuh, W. C. Chien, W. Yan, H. Fei, H. Xu, D. Zhang, Y. Chen, Y. Zhao, Y. Lv, G. Wu, C. Lv, S. K. Arora, C. Ó. Coileáin, C. Heng, C.-R. Chang and H.-C. Wu, ACS Sens., 2019, 4, 2546-2552.

27 M. A. Malik, M. Afzaal and P. O’Brien, Chem. Rev., 2010, 110, 4417-4446 (and references therein).

28 M. D. Khan, M. Aamir, M. Sohail, M. Sher, N. Baig, J. Akhtar, M. A. Malik and N. Revaprasadu, Dalton Trans., 2018, 47, 5465-5473.

29 S. C. Smith, W. Bryks and A. R. Tao, Langmuir, 2019, 35, 2887-2897.

30 (a) S. Mishra and S. Daniele, Chem. - Eur. J., 2020, 26, 9292-9303; (b) I. Bretos, R. Jimenez, J. Ricote and M. L. Calzada, Chem. Soc. Rev., 2018, 47, 291-308; (c) C. Panda, P. W. Menezes and M. Driess, Angew. Chem., Int. Ed., 2018, 57, 11130-11139; (d) S. Mishra and S. Daniele, Chem. Rev., 2015, 115, 8379-8448.

31 (a) S. Gahlot, B. Purohit, E. Jeanneau and S. Mishra, Chem. - Eur. J., 2021, 27, 10826-10832; (b) S. Gahlot, E. Jeanneau, D. Singh, P. K. Panda, Y. K. Mishra, R. Ahuja, G. Ledoux and S. Mishra, Inorg. Chem., 2020, 59, 7727-7738; (c) S. Gahlot, F. Dappozze, D. Singh, R. Ahuja, L. Cardenas, L. Burel, D. Amans, C. Guillard and S. Mishra, Dalton Trans., 2020, 49, 3580-3591; (d) S. Gahlot, E. Jeanneau, F. Dappozze, C. Guillard and S. Mishra, Dalton Trans., 2018, 47, 8897-8905; (e) S. Mishra, D. Du, E. Jeanneau, F. Dappozze, C. Guillard, J. Zhang and S. Daniele, Chem. Asian J., 2016, 11, 1658-1663.
32 (a) Y. Li, H. Xie and J. Tu, Mater. Lett., 2009, 63, 1785-1787; (b) D. Feng, Z.-H. Ge, Y.-X. Chen, J. Li and J. He, Nanotechnology, 2018, 28, 455707; (c) J. Sheng, X. Liu, C. Niu, Y. Sun, Y. Chen, H. Wang, B. Zhang, G. Wang, X. Zhou and G. Han, J. Mater. Chem. C, 2020, 8, 1033310341; (d) B. Pejjai, V. R. Minnam Reddy, K. Seku, M. R. Pallavolu and C. Park, New J. Chem., 2018, 42, 48434853; (e) Y. Liu, D. Hou and G. Wang, Chem. Phys. Lett., 2003, 379, 67-73; (f) P. Ramasamy, P. Manivasakan and J. Kim, CrystEngComm, 2015, 17, 807-813.

33 (a) R. K. Mishra, G. W. Baek, K. Kim, H. I. Kwon and S. H. Jin, Appl. Surf. Sci., 2017, 425, 923-931; (b) G. M. Kumar, F. Xiao, P. Ilanchezhiyan, S. Yuldashev and T. W. Kang, RSC Adv., 2016, 6, 99631-99637.

34 F. Davitt, H. G. Manning, F. Robinson, S. L. Hawken, S. Biswas, N. Petkov, M. van Druenen, J. J. Boland, G. Reid and J. D. Holmes, Adv. Mater. Interfaces, 2020, 7, 1-10.

35 L. Zhao, M. Yosef, M. Steinhart, P. Göring, H. Hofmeister, U. Gösele and S. Schlecht, Angew. Chem., Int. Ed., 2005, 45, 311-315.

36 J. S. Narro-Rios, M. Ramachandran, D. Martínez-Escobar and A. Sánchez-Juárez, J. Semicond., 2013, 34, 2-6.

37 J. R. Thompson, I. Y. Ahmet, A. L. Johnson and G. KociokKöhn, Eur. J. Inorg. Chem., 2016, 2016, 4711-4720.

38 V. Brune, M. Grosch, R. Weißing, F. Hartl, M. Frank, S. Mishra and S. Mathur, Dalton Trans., 2021, 50, 1236512385.

39 V. Brune, C. Hegemann and S. Mathur, Inorg. Chem., 2019, 58, 9922-9934.

40 M. P. Campos, M. P. Hendricks, A. N. Beecher, W. Walravens, R. A. Swain, G. T. Cleveland, Z. Hens, M. Y. Sfeir and J. S. Owen, J. Am. Chem. Soc., 2017, 139, 2296-2305.

41 M. Friebe, A. Mahmood, H. Spies, R. Berger, B. Johannsen, A. Mohammed, M. Eisenhut, C. Bolzati, A. Davison and A. G. Jones, J. Med. Chem., 2000, 43, 2745-2752.

42 M. Sun, C.-Y. Hong and C.-Y. Pan, J. Am. Chem. Soc., 2012, 134, 20581-20584.

43 C. D. Chandler, G. D. Fallon, A. J. Koplick and B. O. West, Aust. J. Chem., 1987, 40, 1427-1439.

44 C. D. Schaeffer, L. K. Myers, S. M. Coley, J. C. Otter and C. H. Yoder, J. Chem. Educ., 1990, 67, 347-349.

45 A. Tzschach, M. Scheer and K. Jurkschat, Z. Anorg. Allg. Chem., 1984, 512, 177-180.

46 A. Tzschach, M. Scheer, K. Jurkschat and A. Zschunke, Z. Anorg. Allg. Chem., 1983, 502, 158-164.

47 A. Tzschach, M. Scheer and K. Jurkschat, Z. Anorg. Allg. Chem., 1984, 508, 73-78.

48 A. Abo-Amer, M. S. McCready, F. Zhang and R. J. Puddephatt, Can. J. Chem., 2012, 90, 46-54.

49 G. Bandoli, A. Dolmella, V. Peruzzo and G. Plazzogna, Inorg. Chim. Acta, 1992, 193, 185-190.

50 G. Bandoli, A. Dolmella, V. Peruzzo and G. Plazzogna, Inorg. Chim. Acta, 1993, 209, 231-234.

51 (a) A. A. Someşan, I. Barbul, S. M. Vieriu, R. A. Varga and C. Silvestru, Dalton Trans., 2019, 48, 6527-6538; 
(b) A. W. Addison, T. N. Rao, J. Reedijk, J. van Rijn and G. C. Verschoor, J. Chem. Soc., Dalton Trans., 1984, 7, 13491356.

52 E. López-Torres, A. R. Cowley and J. R. Dilworth, Inorg. Chem. Commun., 2007, 10, 724-727.

53 A. Verchère, S. Mishra, E. Jeanneau, H. Guillon, J. M. Decams and S. Daniele, Inorg. Chem., 2020, 59, 7167-7180.

54 D. S. McGuinness, D. B. Brown, R. P. Tooze, F. M. Hess, J. T. Dixon and A. M. Z. Slawin, Organometallics, 2006, 25, 3605-3610.

55 A. Jabri, C. Temple, P. Crewdson, S. Gambarotta, I. Korobkov and R. Duchateau, J. Am. Chem. Soc., 2006, 128, 9238-9247.

56 D. S. McGuinness, P. Wasserscheid, W. Keim, D. Morgan, J. T. Dixon, A. Bollmann, H. Maumela, F. Hess and U. Englert, J. Am. Chem. Soc., 2003, 125, 5272-5273.

57 K. Chung, D. Wamwangi, M. Woda, M. Wuttig and W. Bensch, J. Appl. Phys., 2008, 103, 083523.

58 M. Cruz, J. Morales, J. P. Espinos and J. Sanz, J. Solid State Chem., 2003, 175, 359-365.

59 H. Liu and L. Chang, J. Alloys Compd., 1992, 185, 183-190.

60 J. Ru, T. He, B. Chen, Y. Feng, L. Zu, Z. Wang, Q. Zhang, T. Hao, R. Meng, R. Che, Ch. Zhang and J. Yang, Angew. Chem., 2020, 132, 14729-14735.

61 M. D. Khan, M. A. Malik and N. Revaprasadu, Coord. Chem. Rev., 2019, 388, 24-47 (and references therein).

62 M. P. Hendricks, M. P. Campos, G. T. Cleveland, I. J.-L. Plante and J. S. Owen, Science, 2015, 348, 1226-1230.

63 D. Fregona, G. Fragalia and S. Sitran, Main Group Met. Chem., 1995, 18, 269-277.
64 S. Mourdikoudis and L. M. Liz-Marzan, Chem. Mater., 2013, 25, 1465-1476.

65 R. Li, X. Fang, J. Ren, B. Chen, X. Yuan, X. Pan, P. Zhang, L. Zhang, D. Tu, Z. Fang, X. Chen and Q. Ju, Nanoscale, 2021, 13, 12494-12504.

66 D. Martínez-Escobar, M. Ramachandran, A. Sánchez-Juárez and J. Sergio Narro Rios, Thin Solid Films, 2013, 535, 390393.

67 J. Choi, J. Jin, I. G. Jung, J. M. Kim, H. J. Kim and S. U. Son, Chem. Commun., 2011, 47, 5241.

68 A. Tyagi, G. Karmakar, A. Wadawale, A. Y. Shah, G. Kedarnath, A. P. Srivastava, V. Singh and V. K. Jain, J. Organomet. Chem., 2018, 873, 15-21.

69 (a) D. Lu, C. Yue, S. Luo, Z. Li, W. Xue, X. Qi and J. Zhong, Appl. Surf. Sci., 2021, 541, 148615; (b) L. Das, A. Guleria and S. Adhikari, RSC Adv., 2015, 5, 61390.

70 S.-D. Guo, X.-S. Guo, R.-Y. Han and Y. Deng, Phys. Chem. Chem. Phys., 2019, 21, 24620-24628.

71 S. Hünig, P. Kreitmeier, G. Märkl and J. Sauer, Arbeitsmethoden in Der Organischen Chemie, Verlag Lehmanns, Berlin, 2006.

72 STOE X-RED32, 2002.

73 STOE X-SHAPE, 1999.

74 C. B. Hübschle, G. M. Sheldrick and B. Dittrich, J. Appl. Crystallogr., 2011, 44, 1281-1284.

75 G. M. Sheldrick, Acta Crystallogr., Sect. C: Struct. Chem., 2015, 71, 3-8.

76 N. Salvarese, F. Refosco, R. Seraglia, M. Roverso, A. Dolmella and C. Bolzati, Dalton Trans., 2017, 46, 91809191. 